Prepared in cooperation with Northern Arizona University

\title{
Protocol for Installing and Monitoring a RestoreNet Restoration Field Trial Network Site
}

Chapter 18 of

Section A, Biological Science

Book 2, Collection of Environmental Data

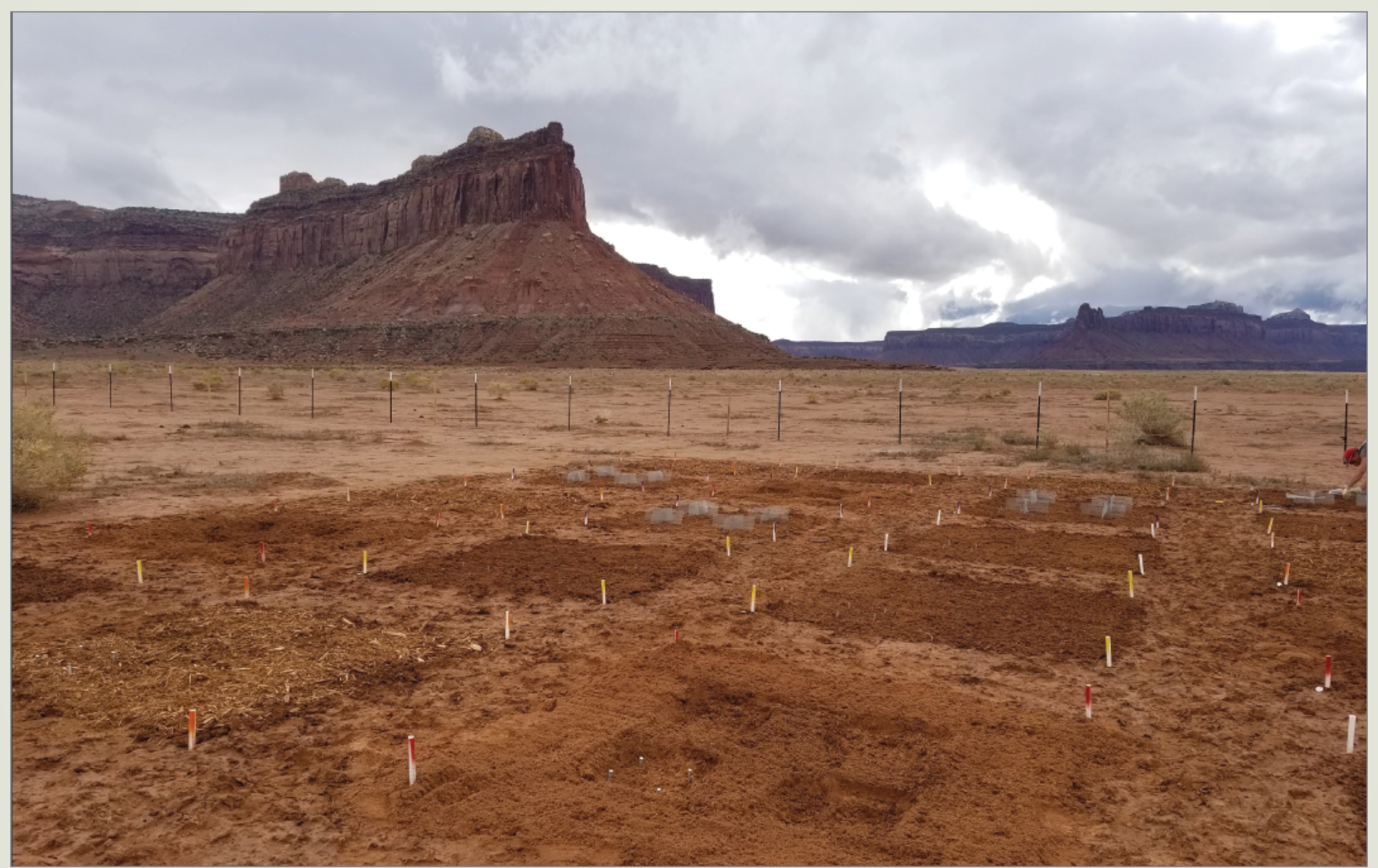

Techniques and Methods 2-A18 
Cover. Photograph showing newly installed RestoreNet seed experiment near Moab, Utah. 


\section{Protocol for Installing and Monitoring a RestoreNet Restoration Field Trial Network Site}

By Katherine M. Laushman, Molly L. McCormick, Seth M. Munson, Kathleen R.

Balazs, and Bradley J. Butterfield

Chapter 18 of

Section A, Biological Science

Book 2, Collection of Environmental Data

Prepared in cooperation with Northern Arizona University

Techniques and Methods 2-A18 


\section{U.S. Geological Survey, Reston, Virginia: 2021}

For more information on the USGS - the Federal source for science about the Earth, its natural and living resources, natural hazards, and the environment-visit https://www.usgs.gov or call 1-888-ASK-USGS (1-888-275-8747).

For an overview of USGS information products, including maps, imagery, and publications, visit https://store.usgs.gov.

Any use of trade, firm, or product names is for descriptive purposes only and does not imply endorsement by the U.S. Government.

Although this information product, for the most part, is in the public domain, it also may contain copyrighted materials as noted in the text. Permission to reproduce copyrighted items must be secured from the copyright owner.

Suggested citation:

Laushman, K.M., McCormick, M.L., Munson, S.M., Balazs, K.R., and Butterfield, B.J., 2021, Protocol for installing and monitoring a RestoreNet restoration field trial network site: U.S. Geological Survey Techniques and Methods, book 2 , chap. A18, 34 p., https://doi.org/10.3133/tm2A18.

ISSN 2328-7055 (online) 


\section{Acknowledgments}

Initial funding for this project was provided by the U.S. Geological Survey (USGS) and the Bureau of Land Management Colorado Plateau Native Plant Program. We are grateful to our RestoreNet collaborators, who granted us permission to enter and work on their land to start this networked experiment and helped us develop applied research questions, including Agua Fria National Monument, Babbitt Ranches, Flying M Ranch, Bar T Bar Ranch, Montezuma Well National Monument, Petrified Forest National Park, Borderlands Restoration Network, Santa Rita Experimental Range, The Jornada Experimental Range, Scottsdale Community College, Bureau of Reclamation at Lake Pleasant, McDowell-Sonoran Conservancy, Tonto National Forest, 29 Palms Inn, Antelope Valley Natural Resource Conservation District, and Tolani Lake Enterprises.

Thanks to our colleagues for helping to write sections of the protocol: Sasha Reed (USGS) and Stella Copeland (Agricultural Research Service) assisted in writing the soils sampling guidelines, Helen Rowe (McDowell-Sonoran Conservancy) developed the reference plot protocol and provided valuable feedback on the data sheet and protocol, Rebecca Mann (USGS) wrote the Connectivity Modifier (ConMod) assembly protocol, and Daniel Winkler (USGS) provided thoughtful feedback on the protocol. Photographs taken by Katherine Laushman, USGS, unless otherwise noted. 


\section{Contents}

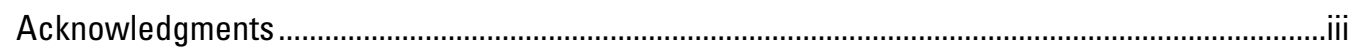

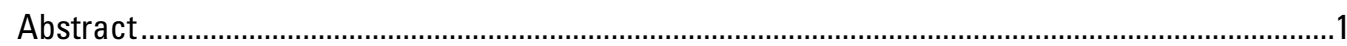

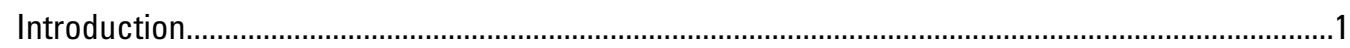

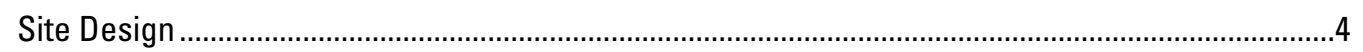

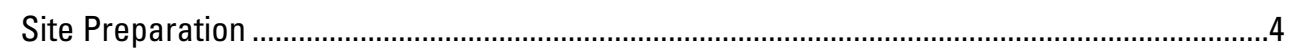

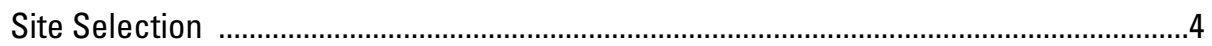

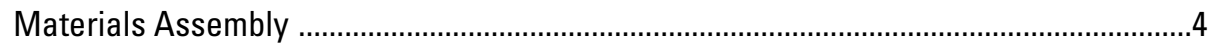

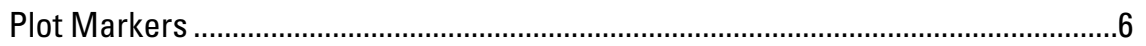

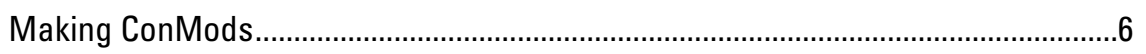

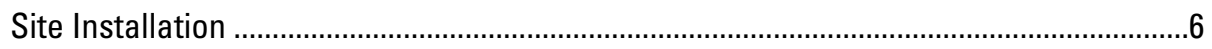

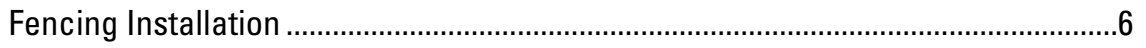

Vegetation Management and Erosion Mitigation.......................................................

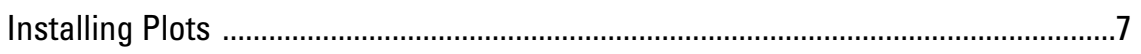

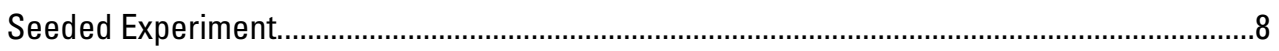

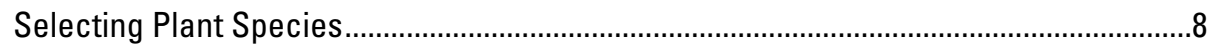

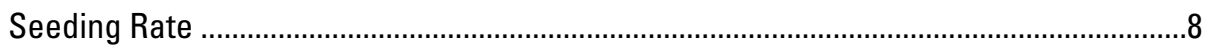

Seed Mixes and Seed Weighing ..............................................................................

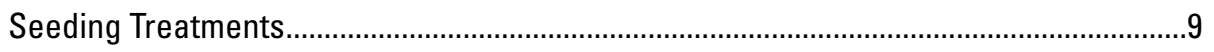

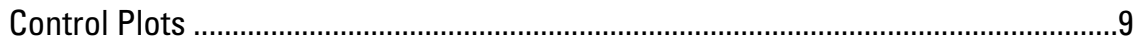

Plot Preparation and Seeding............................................................................

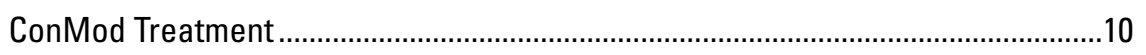

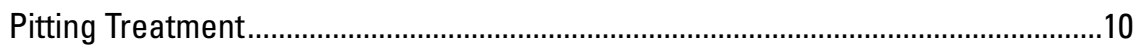

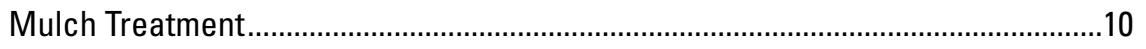

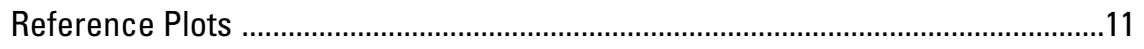

Monitoring Subplot Installation ..........................................................................12

Outplanted-Seedling Experiment ..................................................................................12

Greenhouse Protocol .......................................................................................13

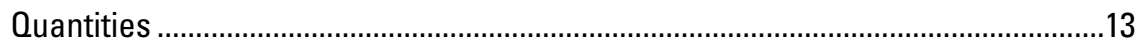

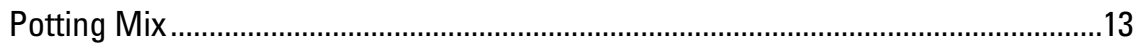

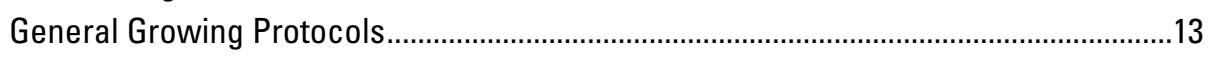

Planting Layout Design ......................................................................................13

Field Planting Protocol .........................................................................................13

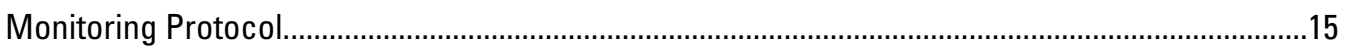

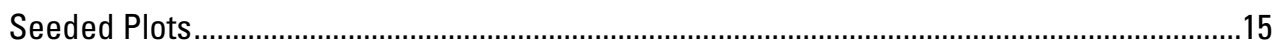

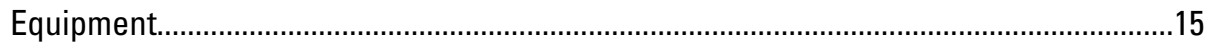

Procedure

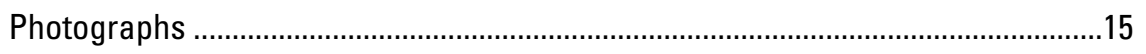

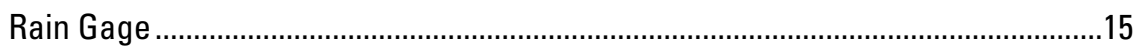

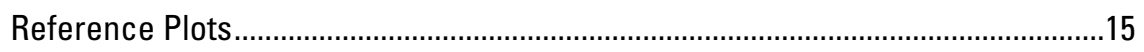

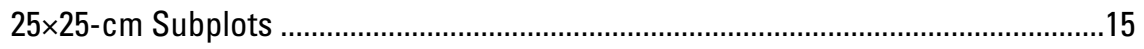

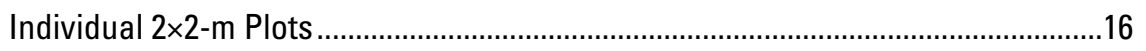

Canopy Cover Measurements .........................................................................16 


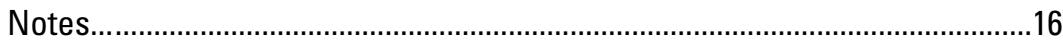

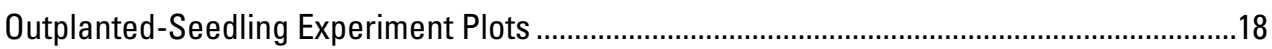

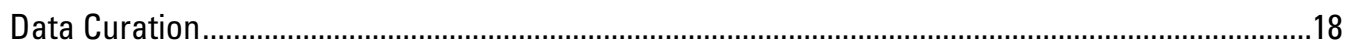

Summary

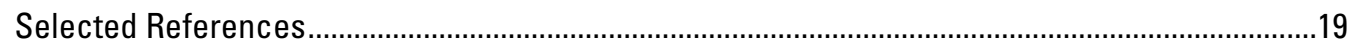

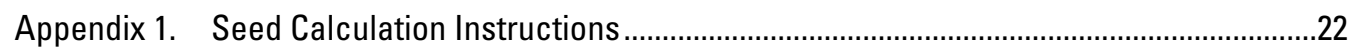

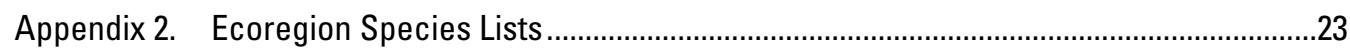

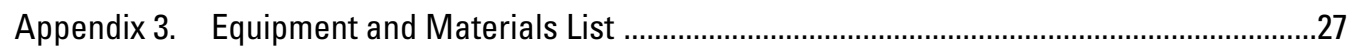

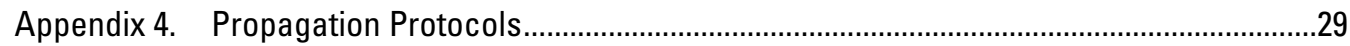

Appendix 5. Seeding Installation Field Data Sheet................................................................30

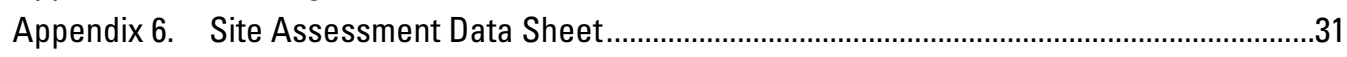

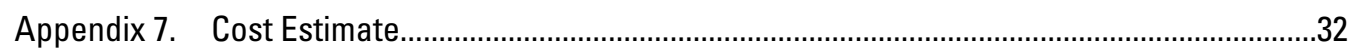

Appendix 8. Example of Germination Monitoring Data Sheet .....................................................33

Appendix 9. Outplanting Layout ..............................................................................................

\section{Figures}

1. Photographs showing seeding treatments for RestoreNet........................................................... 2

2. Map of RestoreNet locations as of August 2020 ……............................................................. 3

3. Photograph showing newly installed RestoreNet seed experiment near Moab, Utah .............. 4

4. Photograph showing seeded experiment with plots laid out in interspaces between Sonoran Desert woody and succulent plants ......................................................................... 4

5. Diagram of layout of a 2,500-square-meter RestoreNet experimental site, including 36 plots for the outplanted-seedling experiment and 36 plots for the seeded experiment ....................... 5

6. Diagram showing timeline for implementation of RestoreNet experiment.................................... 6

7. Photograph showing newly constructed ConMod................................................................ 6

8. Photograph showing wattle used for erosion control .............................................................

9. Photograph of plot set-up. Aisles are 1 meter wide and each corner is markedwith rebar ..... 7

10. Photographs showing seeding RestoreNet plots by hand broadcasting and raking lightly ..... 9

11. Photograph showing installation of one arm of a ConMod with landscape staple.................. 10

12. Photograph showing ConMods installed equidistant from edges of plot, with arms running parallel to edges.................................................................................................................... 10

13. Photograph showing four pits in a plot, with nails marking the pit that will be used for monitoring..

14. Photograph showing mulch treatment at a RestoreNet plot with seeds broadcasted by

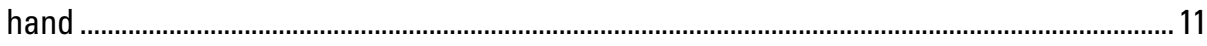

15. Photograph showing reference plots placed adjacent to experimental plots and marked

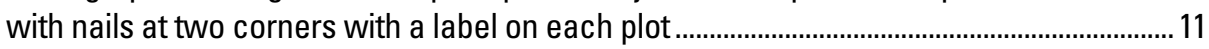

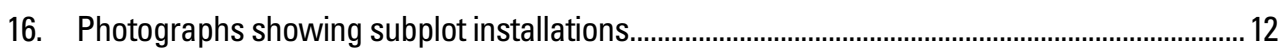

17. Photographs showing steps for site preparation and planting seedlings................................. 14

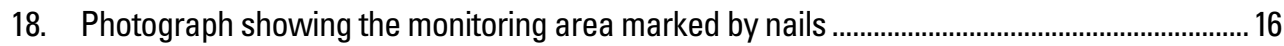

19. Diagram showing guide for estimating percentage cover ....................................................... 17

20. Data sheet example showing information collected at each plot........................................... 17

21. Data sheet example for the outplanted-seedling experiment, showing a single plot with species 4-letter code and space for plant heights and widths 


\section{Appendix Figures}

5.1. Data sheet for seeding installation..................................................................................30

6.1. Data sheet for assessment of proposed RestoreNet site ..................................................31

8.1. Data sheet for monitoring a RestoreNet site ....................................................................33

9.1. Chart showing layout of outplanted-seedling site ..........................................................34

\section{Appendix Tables}

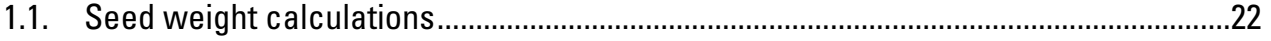

2.1. Chihuahuan Desert ecoregion species.............................................................................23

2.2. Colorado Plateau ecoregion species ................................................................................24

2.3. Mojave Desert ecoregion species.......................................................................................25

2.4. Southeast Arizona Grassland ecoregion species..............................................................25

2.5. Sonoran Desert ecoregion species................................................................................26

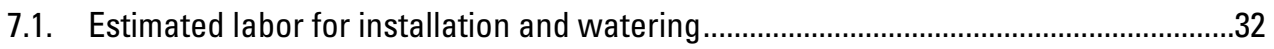

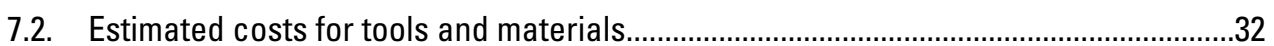

\section{Conversion Factors}

U.S. customary units to International System of Units

\begin{tabular}{|c|c|c|}
\hline Multiply & By & To obtain \\
\hline \multicolumn{3}{|c|}{ Length } \\
\hline foot $(\mathrm{ft})$ & 0.3048 & meter $(\mathrm{m})$ \\
\hline \multicolumn{3}{|c|}{ Area } \\
\hline acre & 4,047 & square meter $\left(\mathrm{m}^{2}\right)$ \\
\hline acre & 0.4047 & hectare (ha) \\
\hline acre & 0.4047 & square hectometer $\left(\mathrm{hm}^{2}\right)$ \\
\hline acre & 0.004047 & square kilometer $\left(\mathrm{km}^{2}\right)$ \\
\hline \multicolumn{3}{|c|}{ Volume } \\
\hline gallon (gal) & 3.785 & liter $(\mathrm{L})$ \\
\hline \multicolumn{3}{|c|}{ Mass } \\
\hline ounce, avoirdupois (oz) & 28.35 & $\operatorname{gram}(\mathrm{g})$ \\
\hline pound, avoirdupois (lb) & 0.4536 & kilogram (kg) \\
\hline
\end{tabular}


International System of Units to U.S. customary units

\begin{tabular}{|c|c|c|}
\hline Multiply & By & To obtain \\
\hline \multicolumn{3}{|c|}{ Length } \\
\hline centimeter $(\mathrm{cm})$ & 0.3937 & inch (in.) \\
\hline millimeter $(\mathrm{mm})$ & 0.03937 & inch (in.) \\
\hline meter $(\mathrm{m})$ & 3.281 & foot $(\mathrm{ft})$ \\
\hline meter $(\mathrm{m})$ & 1.094 & yard (yd) \\
\hline \multicolumn{3}{|c|}{ Area } \\
\hline square meter $\left(\mathrm{m}^{2}\right)$ & 0.0002471 & acre \\
\hline square meter $\left(\mathrm{m}^{2}\right)$ & 10.76 & square foot $\left(\mathrm{ft}^{2}\right)$ \\
\hline \multicolumn{3}{|c|}{ Volume } \\
\hline cubic meter $\left(\mathrm{m}^{3}\right)$ & 6.290 & barrel (petroleum, 1 barrel $=42$ gal) \\
\hline liter $(\mathrm{L})$ & 33.81402 & ounce, fluid (fl. oz) \\
\hline liter $(\mathrm{L})$ & 2.113 & pint $(p t)$ \\
\hline liter $(\mathrm{L})$ & 1.057 & quart (qt) \\
\hline liter $(\mathrm{L})$ & 0.2642 & gallon (gal) \\
\hline cubic meter $\left(\mathrm{m}^{3}\right)$ & 264.2 & gallon (gal) \\
\hline cubic meter $\left(\mathrm{m}^{3}\right)$ & 0.0002642 & million gallons (Mgal) \\
\hline liter $(\mathrm{L})$ & 61.02 & cubic inch $\left(\mathrm{in}^{3}\right)$ \\
\hline cubic meter $\left(\mathrm{m}^{3}\right)$ & 35.31 & cubic foot $\left(\mathrm{ft}^{3}\right)$ \\
\hline cubic meter $\left(\mathrm{m}^{3}\right)$ & 1.308 & cubic yard $\left(\mathrm{yd}^{3}\right)$ \\
\hline cubic meter $\left(\mathrm{m}^{3}\right)$ & 0.0008107 & acre-foot (acre-ft) \\
\hline \multicolumn{3}{|c|}{ Mass } \\
\hline $\operatorname{gram}(\mathrm{g})$ & 0.03527 & ounce, avoirdupois (oz) \\
\hline
\end{tabular}

Temperature in degrees Celsius $\left({ }^{\circ} \mathrm{C}\right)$ may be converted to degrees Fahrenheit $\left({ }^{\circ} \mathrm{F}\right)$ as ${ }^{\circ} \mathrm{F}=\left(1.8 \times{ }^{\circ} \mathrm{C}\right)+32$.

\section{Abbreviations}

$\begin{array}{ll}\text { ConMod } & \text { Connectivity Modifier } \\ \mathrm{K} & \text { potassium } \\ \mathrm{N} & \text { nitrogen } \\ \mathrm{P} & \text { phosphorus } \\ \mathrm{PLS} & \text { pure live seed } \\ \text { RAMPS } & \text { Restoration Assessment and Monitoring Program for the Southwest } \\ \text { TR } & \text { trace } \\ \text { USDA } & \text { United States Department of Agriculture } \\ \text { USGS } & \text { U.S. Geological Survey }\end{array}$





\title{
Protocol for Installing and Monitoring a RestoreNet Restoration Field Trial Network Site
}

\author{
By Katherine M. Laushman, ${ }^{1}$ Molly L. McCormick, ${ }^{1}$ Seth M. Munson, ${ }^{1}$ Kathleen R. Balazs, ${ }^{2}$ and \\ Bradley J. Butterfield ${ }^{2}$
}

\section{Abstract}

RestoreNet is an ecological restoration experiment that is networked across multiple sites, spanning dryland ecosystems in the southwestern United States. The experiment is organized and led by the U.S. Geological Survey's Restoration Assessment and Monitoring Program for the Southwest (RAMPS). This protocol functions to provide guidance to additional partners on how to set up a RestoreNet site and expand the network to new locations. This protocol contains information for site selection, materials acquisition, experiment installation, data collection and monitoring, and data curation. Information includes protocols for the RestoreNet seeded experiment and an additional optional experiment using installed container seedlings initially propagated in a greenhouse. Participation in RestoreNet contributes to a growing body of knowledge on cutting edge ecological restoration methods for use in the southwestern United States to benefit land managers, landowners, and restoration practitioners.

\section{Introduction}

Dryland ecosystems form the largest terrestrial global biome and support one third of the global human population, but they are highly vulnerable to land degradation caused by disturbance and climate change (Millennium Ecosystem Assessment, 2005, Intergovernmental Panel on Climate Change [IPCC], 2018). Invasion by nonnative species, wildfire, drought, and other disturbances are growing rapidly in extent and frequency, creating novel ecosystem conditions that can outpace the knowledge base of local land managers. Despite widespread demand for dryland restoration and rehabilitation, there is often sparse information available to help land managers effectively establish native vegetation and stabilize soils across drylands of the United States. In addition, the success of restoration activity and recovery of dryland systems after disturbance is low (Chambers, 2000; James and others, 2011; Larson and others, 2015). A more thorough understanding of how drylands recover after disturbance, and what actions can be taken to mitigate

\footnotetext{
${ }^{1}$ U.S. Geological Survey.

${ }^{2}$ Northern Arizona University.
}

harsh growing conditions and promote plant establishment and growth, can help guide ecosystem recovery. To respond to this need, the U.S. Geological Survey (USGS) is working together with land management agencies and organizations, academic institutions, and private landowners to co-produce RestoreNet, a network of restoration field trial sites spanning public and private lands in the southwestern United States. The network systematically tests restoration treatments across a broad range of landscape, soil, and climate conditions.

RestoreNet is a project of the Restoration Assessment and Monitoring Program for the Southwest (RAMPS), which is an interdisciplinary group of scientists, land managers, and restoration practitioners coordinated at the USGS Southwest Biological Science Center. The mission of RAMPS is to strengthen restoration and rehabilitation outcomes in the southwestern United States. by providing science and guidance on effective strategies. RAMPS facilitates collaborative, innovative, and dynamic research, which generates a hub of science-based information and tools to support restoration decision-making.

RestoreNet was developed in response to a growing need from land managers across the Southwest for effective restoration protocols, to assess and monitor restoration treatments, and to provide scientific rigor in understanding restoration outcomes. RestoreNet also provides an outlet for the ecological restoration research community to share new knowledge, technologies, and tools needed by land managers. RestoreNet, therefore, connects science to land management to meet restoration objectives and produce restoration solutions that are scalable to multiple levels of disturbance and are transferable across the Southwest and beyond.

RestoreNet benefits land managers in the following ways:

1. RestoreNet co-produces science to engage land managers from the beginning of projects and to develop actionable restoration treatments.

2. RestoreNet provides demonstration sites for knowledge sharing of restoration methods that are successful and shows a clear proof of concept for improving land conditions.

3. RestoreNet uses small restoration plots to test multiple restoration treatments and determine best management practices in a low-risk environment, so that effective treatments can be applied to support large restoration efforts when they are needed. 
RestoreNet improves restoration outcomes in the following ways:

1. RestoreNet provides guidance on priority species for restoration based on the relative performances of species in different environmental conditions.

2. RestoreNet advances the science of dryland ecology and restoration through studying the drivers of variation in the success of seeding and other restoration treatments across space and time.

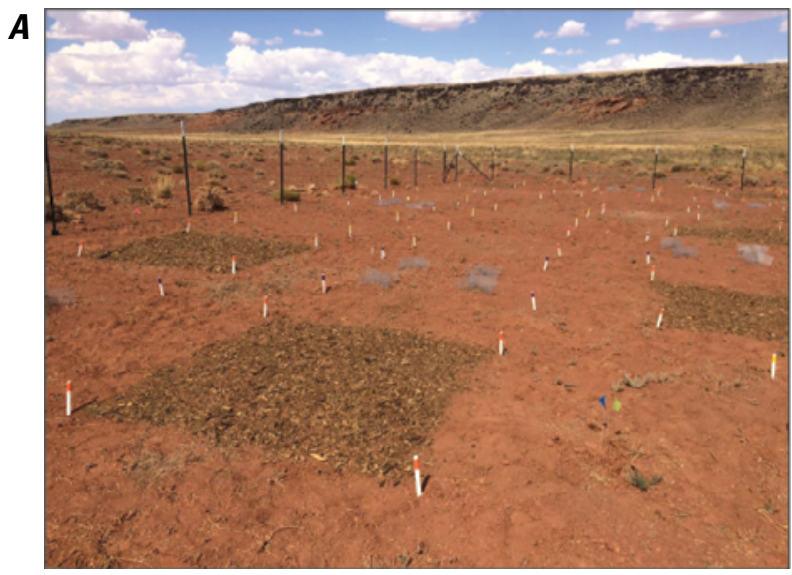

C
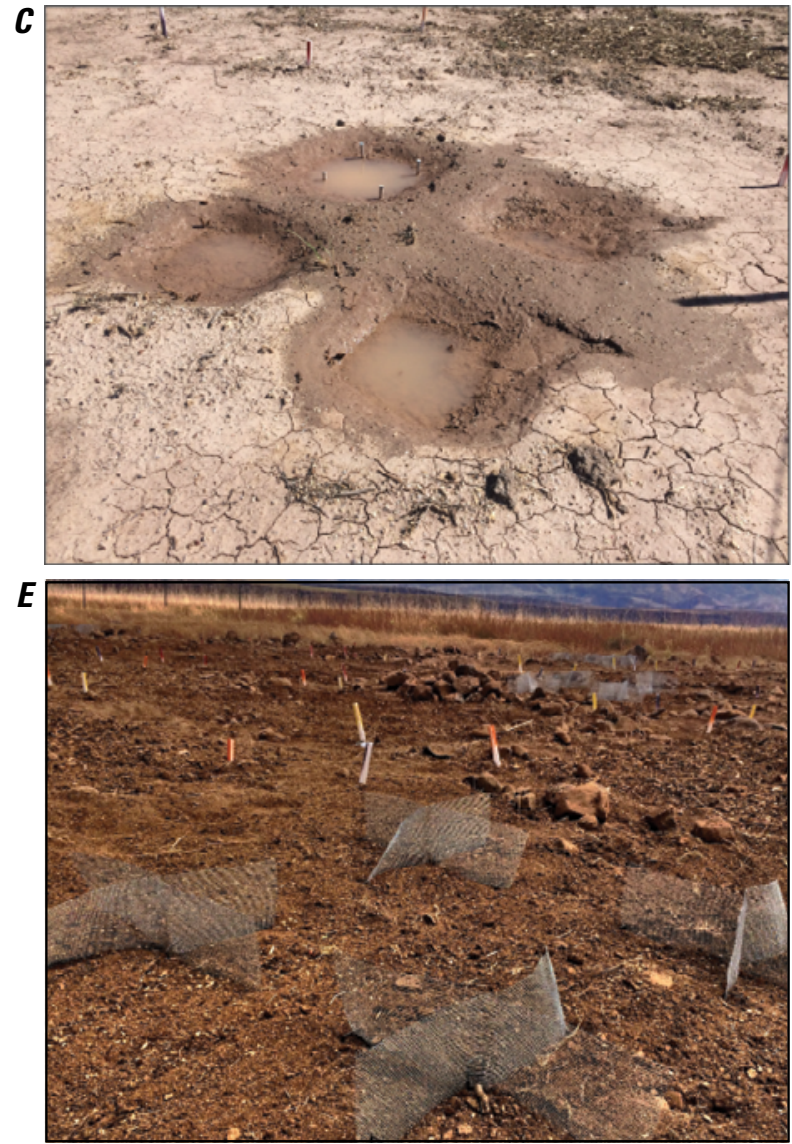

3. RestoreNet demonstrates alternative restoration actions that have not been previously considered.

4. RestoreNet defines how restoration results in improvements to ecosystem function.

Each RestoreNet site contains scientifically rigorous experiments that test suitable seed mixes and treatments that promote plant establishment and growth (fig. 1). The treatments at all RestoreNet sites include seed mixes of native species that are adapted to both cooler and warmer site conditions, coupled
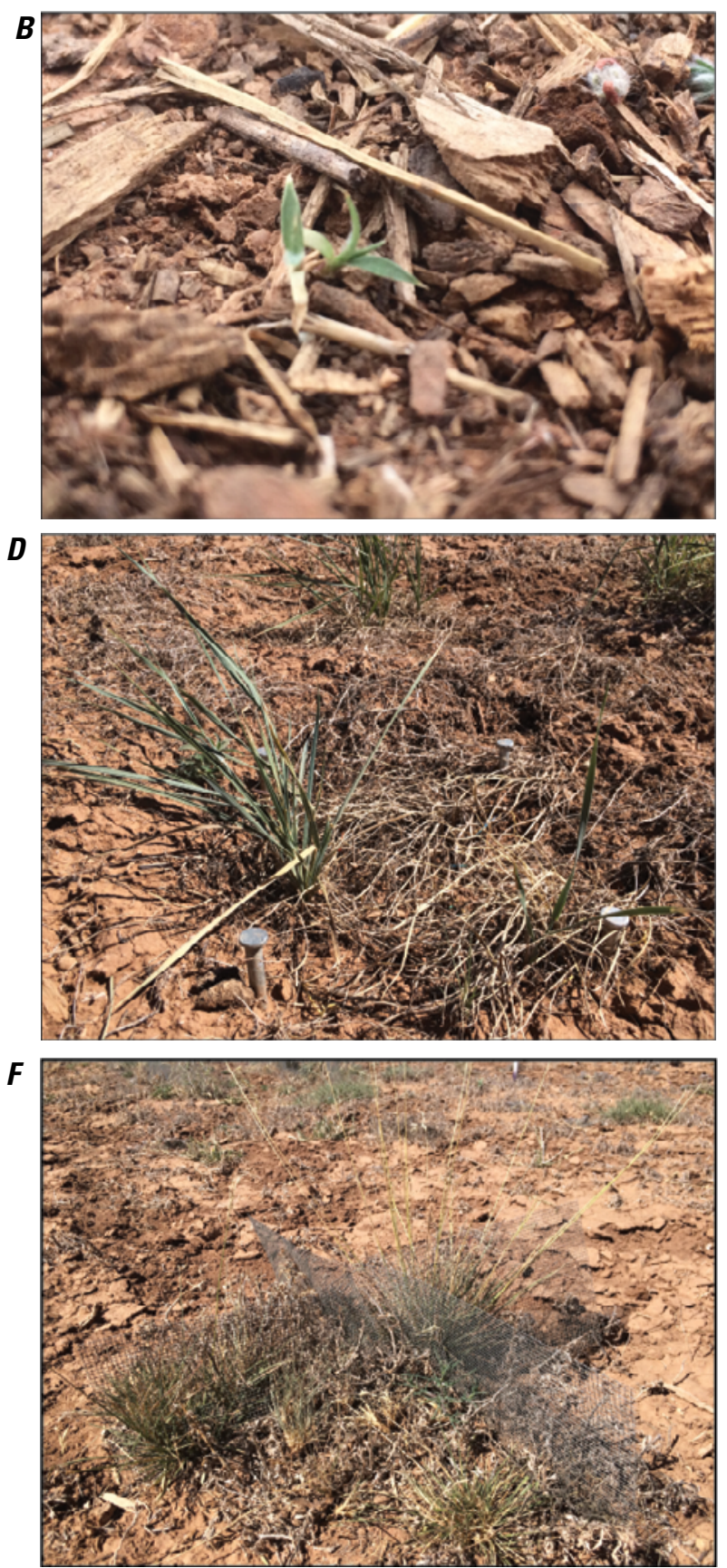

Figure 1. Photographs showing seeding treatments for RestoreNet. Wood mulch can be applied to retain soil moisture $(A, B)$. Pitting (digging small depressions) is a proven method that borrows from indigenous ecological knowledge to capture precipitation and retain seeds $(C, D)$. Connectivity Modifiers (ConMods) are small nurse plant structures that inhibit erosion and create microsites to increase seedling establishment $(D, E)$. Photographs by Molly McCormick, Rebecca Mann, and Katherine Laushman, U.S. Geological Survey. 
with ground modifications (below ground, at-surface, and above ground) that increase water retention. Additional treatments can also include outplanted seedlings from a greenhouse, soil amendments, seed provenance (origin), seed enhancements, and herbicide and mechanical treatments to suppress invasive species. The RestoreNet network, as of summer 2020, contains 24 experimental sites distributed across dryland ecoregions in the southwestern United States (fig. 2). Each RestoreNet site should contain space to address questions driven by local landowners, land managers, or researchers. In addition, each experimental site should allow space for future research questions, so that scientific inquiry relevant to land management actions can build upon itself over time and more nuanced scientific guidance for dryland restoration can be achieved.

RestoreNet protocols are intended for land managers, landowners, or restoration scientists and practitioners who want to install an experiment and join the network. Reasons to join the network include seeking out best practices for improving and recovering degraded land condition, opportunities to conduct small-scale tests to inform future larger scale restoration

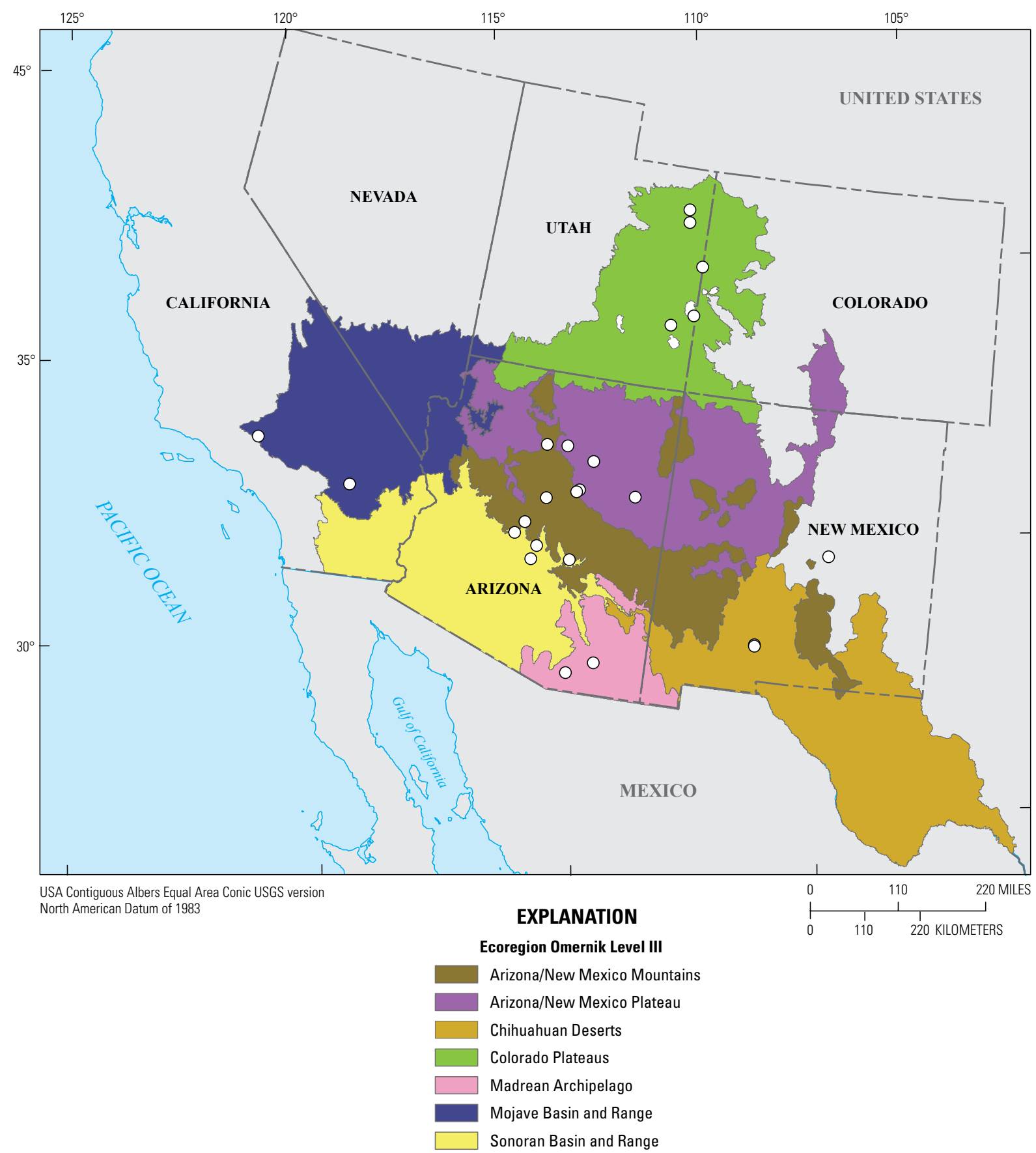

Figure 2. Map of RestoreNet locations as of August 2020. Ecoregions from Omernik (1995). 
efforts, creation of a demonstration site to show practices that are effective, understanding the role of environmental conditions on treatment effectiveness, contributing to or accessing data, or harnessing the experimental network for additional value-added research questions.

This report contains the protocols for site selection, building, monitoring, and maintaining a RestoreNet experimental site. At a minimum, a RestoreNet site needs to include a standardized seeded experiment; with the option to include an additional experiment of outplanting seedlings grown in a greenhouse. To be a part of RestoreNet, the protocols outlined below should be followed closely to ensure that results are comparable across the network.

\section{Site Design}

A RestoreNet site is composed of a series of $2 \times 2$-meter (m) experimental plots, designed to test a suite of restoration treatments in an area requiring recovery of degraded vegetation and soil conditions. See appendix 7 for an estimate of hours and costs of preparing and installing a site. The seeded experiment of RestoreNet involves seeding 36 plots, broadcast by hand, with two different seed mixes composed of species adapted to cool or dry climates relative to local site conditions, crossed with additional treatments to increase water infiltration and modify site characteristics: Connectivity Modifiers (ConMods, which nurse plant structures that inhibit erosion and create microsites to increase seedling establishment), pits, and mulch (fig. 1). Seed-only plots and no-seed control plots are also installed to compare with water retention treatments. In addition, sixteen $25 \times 25$-centimeter $(\mathrm{cm})$ reference plots are added to assist in identification of seedlings.

The optional outplanted-seedling experiment requires outplanting 36 seedlings in each of 36 outplanting plots. Plants

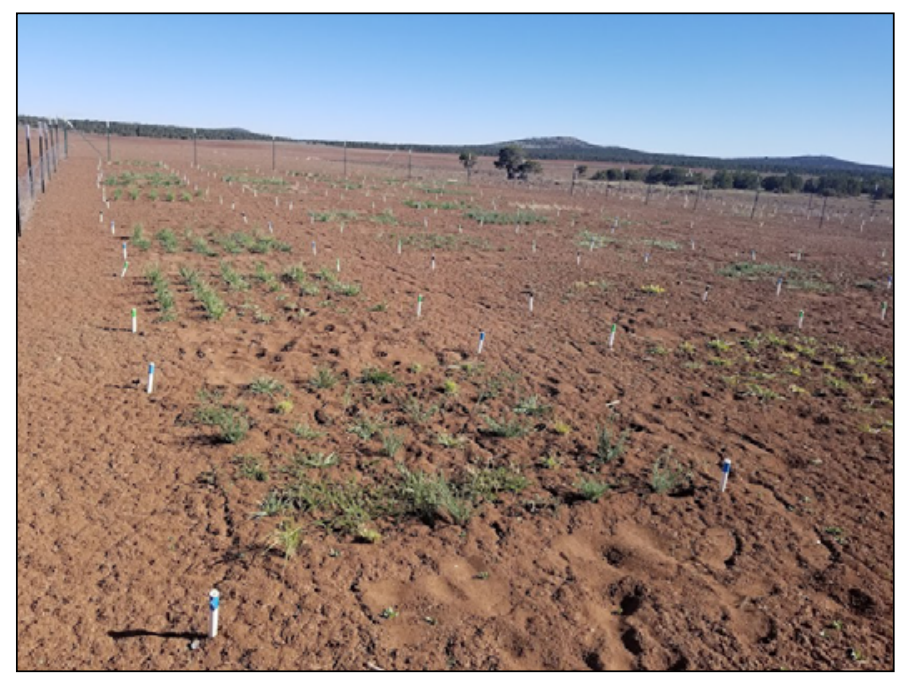

Figure 3. Photograph showing outplanted plots near Flagstaff, Arizona. are arranged into monocultures (single species) or polycultures (multiple species), in part to assess how transplanted individuals differentially survive in competition with the same or other species at the site (fig. 3). Installing a RestoreNet experiment requires selecting an appropriate site, assembling all materials needed, installing the seed experiment, and installing the outplantedseedling experiment if desired.

\section{Site Preparation}

\section{Site Selection}

The first step in developing a RestoreNet site is to identify an area of land to install the experiment. The area should already be degraded by containing low or no native vegetation, and ideally be representative of areas where future restoration can take place within a management unit. The area should also be able to support native vegetation with relatively intact soils and contain roughly 2,500 square meters $\left(\mathrm{m}^{2}\right)$ of flat surface, ideally configured in a $50 \times 50$-m square or as needed to accommodate existing native vegetation (figs. 4, 5). The "Field Assessment Data Sheet" is available for initial site visits to ensure all these criteria are met (appendix 6). Any necessary permissions and permits to use the land should be obtained prior to installing the experiment. Enough time should be allowed for site selection and permitting, as this process can take up to a year or more (fig. 6).

\section{Materials Assembly}

Once a site has been selected, the treatment materials and site need to be prepared. Treatment materials include ConMods, rebar and PVC pipe to mark the plots, mulch, and fencing material to build an herbivore exclosure fence around the experimental site. Depending on pretreatment site conditions, existing vegetation

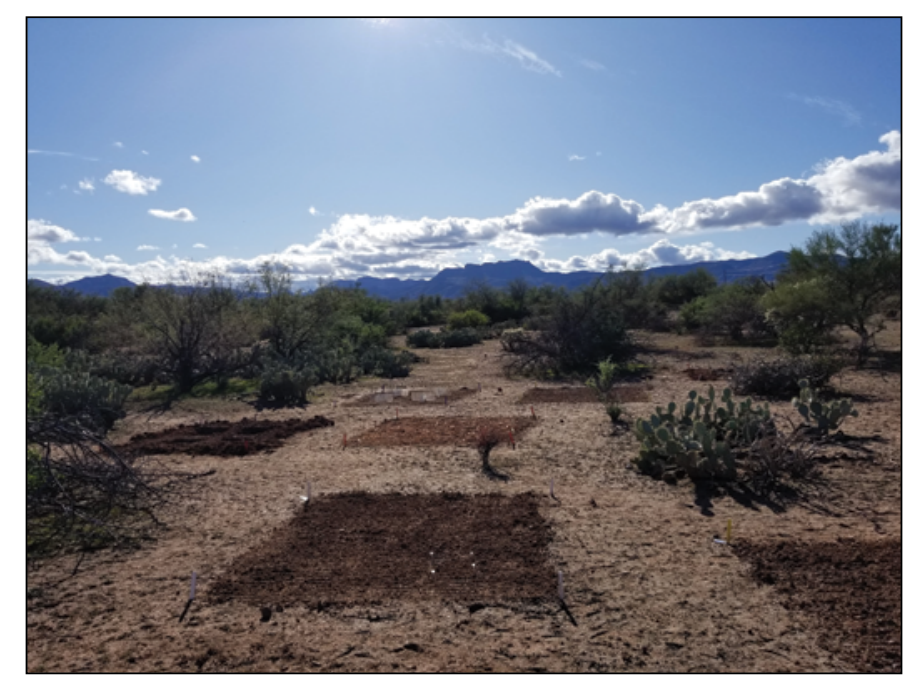

Figure 4. Photograph showing seeded experiment with plots laid out in interspaces between Sonoran Desert woody and succulent plants. 
Distance, in meters

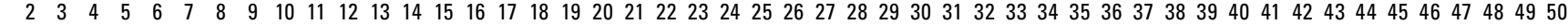

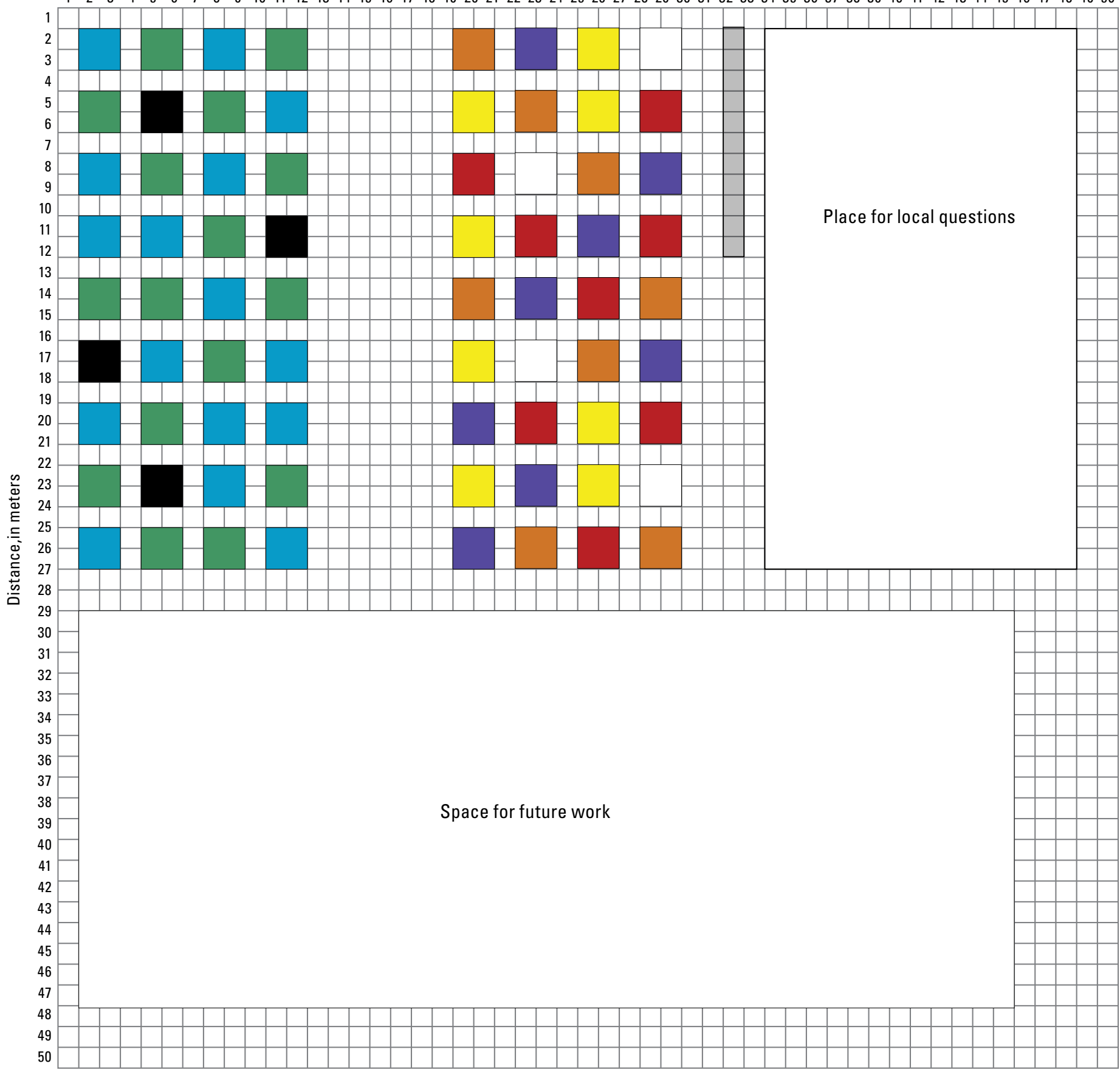

EXPLANATION

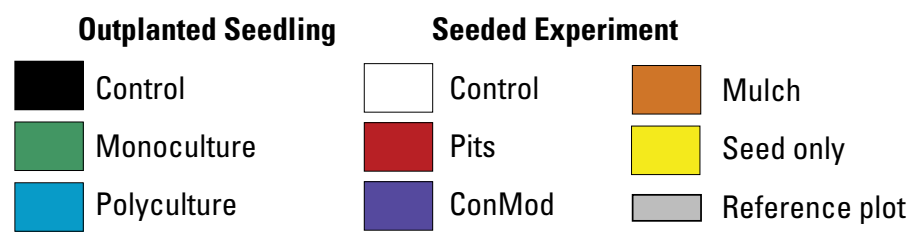

Figure 5. Diagram of layout of a 2,500-square-meter $\left(\mathrm{m}^{2}\right)$ RestoreNet experimental site, including 36 plots for the outplanted-seedling experiment (left) and 36 plots for the seeded experiment (right). 
Figure 6. Diagram showing timeline for implementation of RestoreNet experiment.

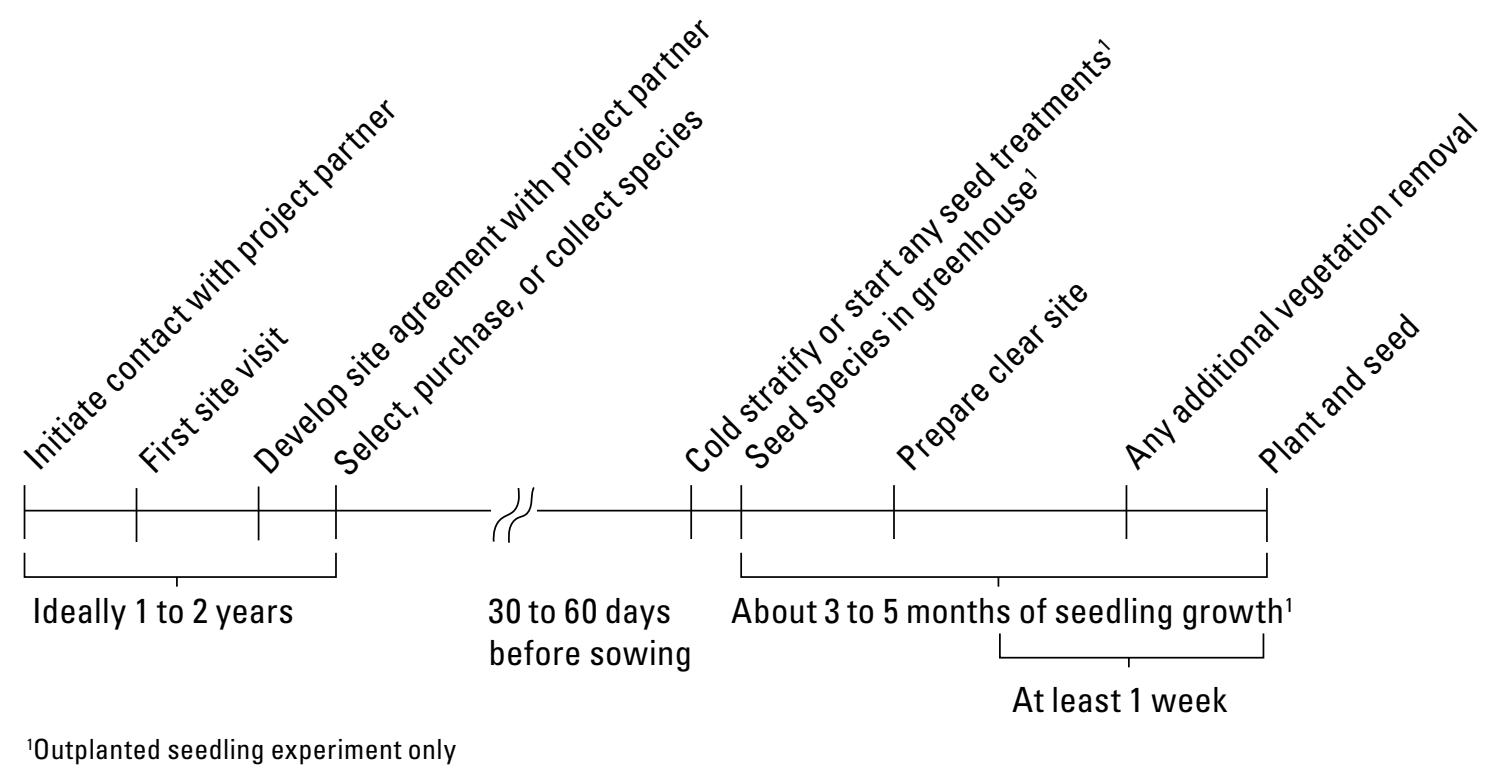

may need to be removed and erosion-control structures added before installing the plots. For a complete materials list, see appendix 3 .

\section{Plot Markers}

Each of the 36 plots in a RestoreNet experiment needs to be marked at four corners with permanent, durable plot markers. Use 38-cm lengths of 1-cm-diameter rebar for safety and ease of relocation. PVC pipe is the most durable option for fitting over the rebar, and orange rebar caps can be used in addition to prevent PVC pipe from blowing off. PVC-pipe covers should ideally be $15 \mathrm{~cm}$ in length and 12.7 millimeters $(\mathrm{mm})$ in diameter and can be marked with a band of spray paint to correspond to a treatment. The smaller reference plots to identify seedlings should be marked at opposite corners with spike nails (a total of 32 spike nails are needed to mark 16 reference plots).

\section{Making ConMods}

ConMods are constructed out of $0.3-\mathrm{cm}$-mesh hardware cloth. Each ConMod is composed of two identical pieces of hardware cloth, cut to be $15 \mathrm{~cm}$ wide and $45 \mathrm{~cm}$ long. A $7.5-\mathrm{cm}$ slit is cut into the middle of each piece of hardware cloth to allow them to fit together and create a three-dimensional ConMod (fig. 7). More detailed protocols for creating ConMods are available upon request.

\section{Site Installation}

Site installation includes fencing construction, ground preparation, and plot installation. Fencing is constructed to prevent or reduce herbivory and trampling. Ground preparation includes removal of existing vegetation and adding any structures to mitigate erosion potential. Plot installation includes marking the plots and installing the treatments.

\section{Fencing Installation}

Each site that might be exposed to livestock grazing or herbivory from wildlife requires a perimeter fence. Where possible, it is ideal to choose a site that is already fenced or where an existing fence can be tied into the RestoreNet site. If landowners have fencing requirements or protocols, follow their standards. It is especially important to follow local guidance for all types of herbivory and reduce granivore pressure if possible. The RestoreNet standard fencing protocol was created to exclude cattle and to deter deer and elk. The protocol also contains alternative fencing options for rodents, rabbits, and javelina. A list of materials recommended for fencing can be found in appendix 3 . Refer to figure 5 for a sketch of the site layout.

To exclude cattle, build a 3- or 4-strand barbed-wire fence along the site perimeter (typically $50 \times 50 \mathrm{~m}$ ). Some landowners may recommend a specific number of wire strands or request a smooth wire for the bottom strand to allow for pronghorn movement. To exclude rabbits from the entire site or from only outplanted plots, add chicken wire to the fence structure, and bury the chicken wire at least $15 \mathrm{~cm}$ below the soil surface to deter

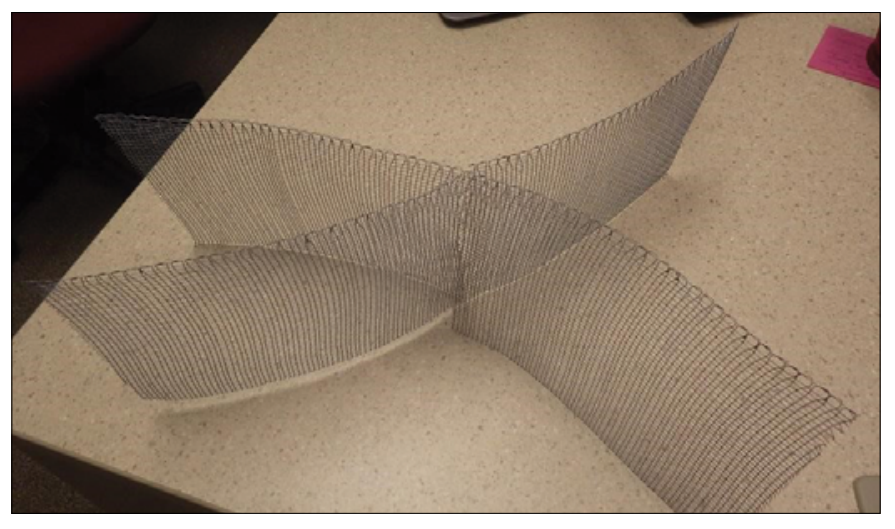

Figure 7. Photograph showing newly constructed Connectivity Modifier (ConMod). 
digging. Hardware cloth may be used with additional flashing bolted to the top to deter granivory by small rodents, if deemed necessary by local land managers.

If weather data is not available for the site, or site visits will not be frequent enough to collect onsite precipitation data, install a rain gage. Place about $1 \mathrm{~cm}$ of oil (such as vegetable oil or machine lubricant) in the rain gage to prevent water from evaporating from the gage.

\section{Vegetation Management and Erosion Mitigation}

Remove all existing vegetation and large rocks from site, using cutter-mattocks, McLeods (rakehoes), loppers, and shovels. If necessary, apply post-emergent herbicide to existing vegetation, waiting at least 7 days after spraying before removing vegetation. Be sure to obtain approval from a land manager or private landowner before using herbicide and follow all recommended safety guidance. If the site is on a slope, plots should be protected from sheet flow and erosion by placing straw wattles (fig. 8) or other erosion-control features as necessary.

\section{Installing Plots}

After the fence is erected, plots can be installed. The seeded experiment and outplanted-seedling experiment each contain thirty-six $2 \times 2$-m plots (fig. 5 ).

\section{Assemble plots using the following steps:}

- Use measuring tapes to set up $2 \times 2-\mathrm{m}$ plots with 1 -m aisles between plots and inside fence lines. If possible, arrange plots as shown in figure 5, but avoid placing plots in areas with large rocks or large recently removed vegetation (fig. 9).

- Use a $2 \times 2-m$ PVC-pipe quadrat frame to ensure square plots; hammer in rebar for each of the four corners until the rebar is approximately $12 \mathrm{~cm}$ above ground.

- Randomize plot treatments by placing the colored PVC-pipe pieces or other plot markers that indicate treatment type on all the plot corners. Use metal numbered tags to label each plot with a distinct number, following a logical order within site rows.

- Install reference plots for identifying seedlings.

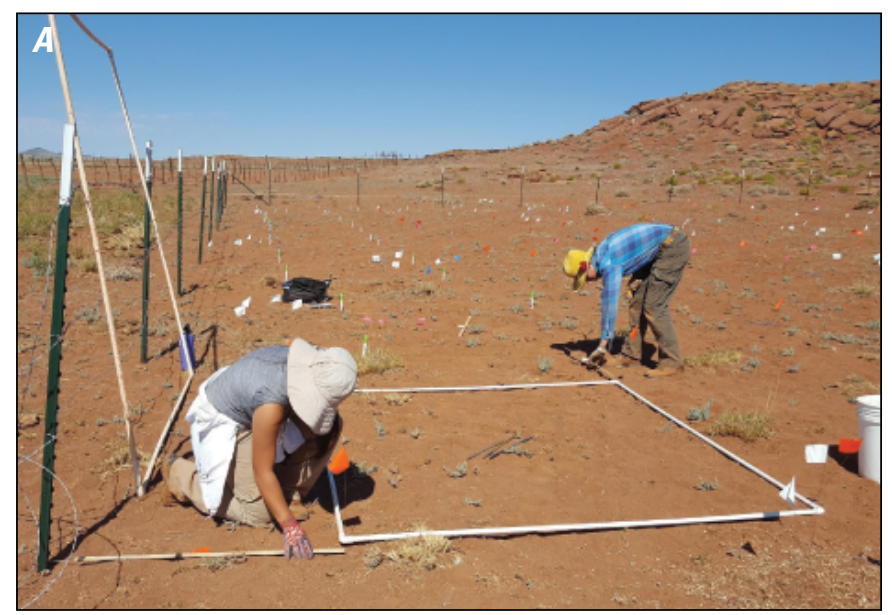

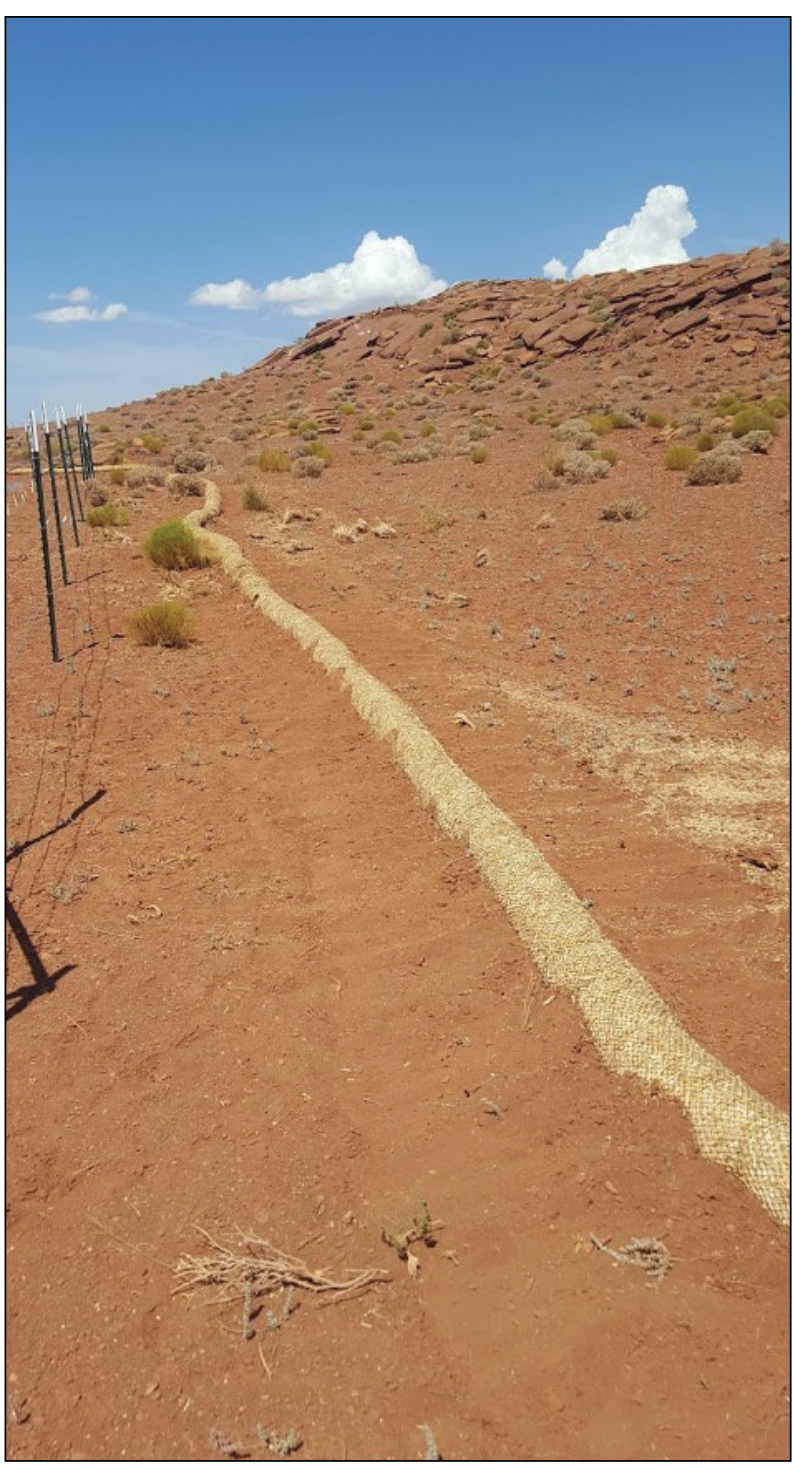

Figure 8. Photograph showing wattle used for erosion control.

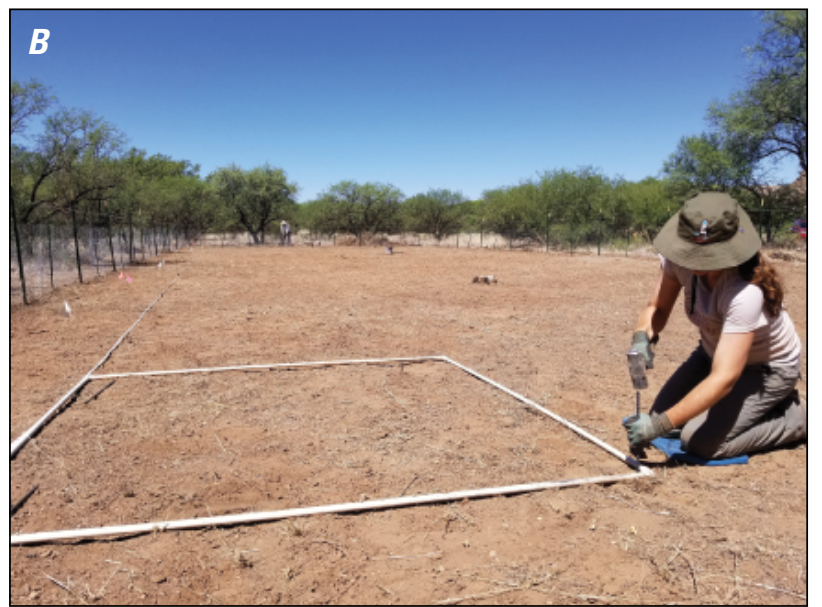

Figure 9. Photograph of plot set-up. Aisles are 1 meter wide $(A)$ and each corner is marked with rebar $(B)$. 


\section{Seeded Experiment}

\section{Selecting Plant Species}

The plant species used in the experiment should contain a mix of mostly perennial grasses, forbs (herbaceous dicots), and, when relevant, priority restoration sub-shrub and shrub species. Annual species can be used where they compose a large part of the reference plant community and precipitation is very low and highly variable, such as in the Mojave Desert. The species pool should be selected by consulting existing species lists, including those from nearby RestoreNet sites, and local expert knowledge (see further guidance in list below). The mix should include species commonly known to be "workhorse" or important species for restoration in the area (Havens and others, 2015). At each experimental site, 2 seed mixes, each containing 8 species for a total of 16 species, should be used for the experiment. Here are some guiding steps and questions to help with species selection:

1. Obtain relevant lists of species:

A. Look at species or genera used in other locations of RestoreNet that could be appropriate for the chosen site (appendix 2).

B. Research any limitations to using species at the chosen site; for example, does the land manager have a list of known species that occur at the site or may be noxious or undesirable that should be cross-referenced?

C. Determine the priority restoration species for the ecoregion:

I. Is there a land management agency or seed collection crew in the ecoregion of the chosen site with a list of priority species? Be sure this list contains species known to be successful for restoration and is not an opportunistic list of species for wild collections.

II. What are the dominant species at the chosen site? Look at a nearby undisturbed reference site or determine the species that occur in the ecoregion level IV (Omernik, 1995) or Ecological Site (U.S. Department of Agriculture [USDA] Natural Resources Conservation Service, 2003) in which the chosen site occurs.

III. Which species are important from the perspective of local land managers and restoration practitioners? These may include those that enhance wildlife and pollinator habitat, forage for livestock, ecosystem services (for example, improve soil stability), and (or) resilience to ecosystem change (for example, fill gaps in niche space left by species in decline).

2. Create a draft species list and review with experts and partners to balance issues discussed above and take notes on why certain species were included. Discussion points include the following questions: How do you align priorities of different sites? What if a species is native to one site but not another? How do you reconcile this? Which ones are workhorse species? Which ones might do better in a changing climate?

3. Look for seed from regional or local seed growers or develop a seed collection plan (as needed). Limiting factors in species selection may include seed availability from seed vendors or creating enough time for conducting seed collection.

4. Obtain final approval of species list from researchers, land managers, landowners, or other collaborators before conducting seeding.

\section{Seeding Rate}

After selecting the species lists, calculate the seeding rate based on information from vendors and restoration practitioners about average seeding rate in pure live seed (PLS).

- If species have already been used at an existing RestoreNet site, use the previously recommended seeding rate (see appendix 2).

- Ask the vendor if they have a preferred seeding rate and use the upper limit if a range is given to increase the probability of successful germination. Internet searches can produce common seed rates for many species.

- Use the Seed Calculation Instructions (appendix 1) to calculate the amount of seed needed for each species.

After acquiring seed, store it in a refrigerator below $10^{\circ} \mathrm{C}$ to keep it viable. For wild-collected seed, perform seed viability tests to calculate the PLS rate.

\section{Seed Mixes and Seed Weighing}

Divide the species pool into two seed mixes for the experiment: species adapted for relatively cool or current conditions and species adapted to warmer conditions. The seed mix of species adapted to warmer conditions is based on the expectation that climate of the Southwest will become warmer and drier based on global climate models (Seager and others, 2007). These climate suitabilities are made based on estimates of temperature niches for each species.

The cool mix can be a species list that is currently recommended for the site. A warm seed mix can be selected using multiple approaches: (1) knowledge of what grows in warmer and (or) drier areas within a management unit represented by the selected RestoreNet site; (2) selecting from a known seed mix list from a warmer and (or) drier location that occurs on similar soils and landscape position (that is, climate is different but other environmental variables are the same); (3) overlaying species distribution maps with climate variables for the chosen and nearby sites; and (4) using a seed $\times$ climate selector tool that can be provided upon request. 
After the species are divided into two mixes, the seeds can be packaged for easy seeding into each plot at the study site. Combine species for each plot into their own resealable plastic bag and make an extra bag of each species for the reference plots. This will create 16 bags of each seed mix for a total of 32 bags ( 4 control plots are not seeded) used for treatment plots, plus 16 bags of species for the reference plots. See the Seed Calculation Instructions (appendix 1). Use a scale that can measure to a tenth or a hundredth of a gram to weigh the seeds. For each species, weigh the amount needed to seed one plot and place it into 1 of 16 bags. Label the bag with the following information: site name (if seeding more than one), seed mix, treatment, and species code of the species weighed to keep track of the contents of each bag before weighing the next species. Measure one more bag of each species for use in the reference plots and label with the 4-letter species code; do not combine species when weighing reference plots. After adding all 8 species to a bag, it should read, for example: "Site A, Warm Mix, Mulch," and the 4-letter codes of each of the 8 species in the bag. Store these bags in a refrigerator until installation in the field. Be sure to use a cooler to transfer seed from the refrigerator to the field to keep the seeds viable.

\section{Seeding Treatments}

The restoration treatment plots receive one of five treatments: (1) control, (2) seed only, (3) seed with ConMod, (4) seed with pitting, and (5) seed with mulch.

\section{Control Plots}

There are two types of control, or reference, plots:

- Plots that do not receive seed (four replicate plots). These plots do not receive any seed or treatment but are cleared of existing vegetation and raked similar to other plots.

- Plots that receive seed only but no additional treatments. Four plots receive seed only for each seed mix ( 4 plots $\times 2$ seed mixes $=8$ total plots $)$ and are installed according to the seeding protocol below.

\section{Plot Preparation and Seeding}

All plots should be raked with a rake or McLeod to homogenize the soil and level the plot. Any regrowth of existing vegetation from the site preparation clearing should be removed before seeding. Use the Installation Field Data Sheet (appendix 5) to record pre-seeding vegetation and substrate (rock, gravel, bare ground, soil crust, and so on) cover of each plot. Any small amounts of remaining vegetation and substrate cover should be noted after site clearing.

The following seeding procedure will be used for the seed-only, ConMod, pitting, and mulch treatments: the ConMod and mulch treatments will be installed after seeding; the pitting treatment will be completed before seeding. Randomly assign seed mixes to the plots. Record which seed mix each plot gets on the Installation Field Data Sheet (appendix 5), making sure that each treatment receives four replicates of each seed mix. When seeding, keep seeds in a cooler until they are installed and do not lay bags of seed in the sun.

To seed a plot, bulk up the seeds in the seed mix by increasing their volume inside the bags with local dry soil to a ratio of two parts dry soil to one part seed. Mix this in the bag or in a separate bucket. The dry soil helps give some bulk and weight to the mix for broadcast seeding by hand. After mixing, sprinkle the mixture evenly over the plot by hand (fig. 10A). To help get an even amount on the plot, divide the plot into four quadrants and seed each quadrant using about one quarter of the amount of the seed and soil mix.

After spreading the seed, incorporate the seeds into the soil by gently raking seeds in with a rake or McLeod and tamping the soil down with a McLeod or tamper to a depth of $2 \mathrm{~cm}$ (fig. 10B). Control plots that do not receive seed should have the same pre- and post-treatments, such as raking, that all other plots get. After seeding, apply mulch and ConMod
$\boldsymbol{A}$

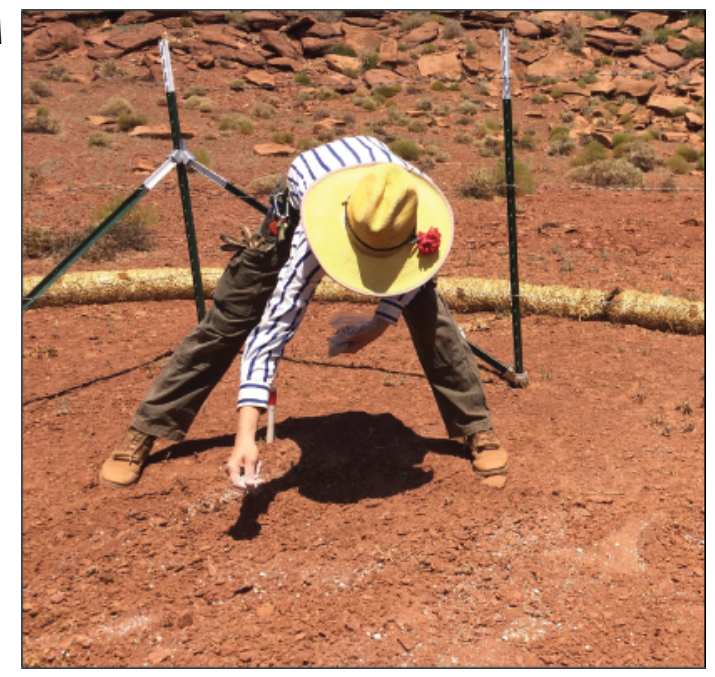

B

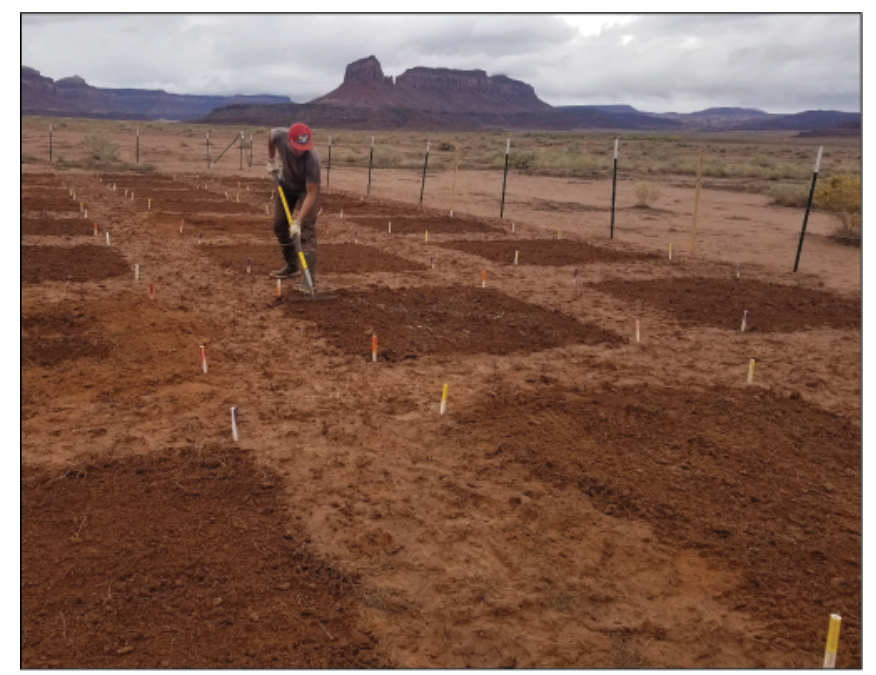

Figure 10. Photographs showing seeding RestoreNet plots by hand broadcasting $(A)$ and raking lightly $(B)$. 
treatments (see details in the "ConMods" section below). Seed-only plots do not receive additional treatments.

\section{ConMod Treatment}

Eight plots per site receive ConMod treatments. Install four ConMods in each of the plots using even spacing among ConMods so that there is one ConMod within each of the four quadrants of the plot. Insert one $15-\mathrm{cm}$ ground staple into the center of the ConMod, so that it goes through two of the arms when unfolded. Hammer the center staple into the ground.

Unfold the ConMod, so that the four arms are extended at right angles and so the ConMod is standing upright on the soil, with the arms extending parallel to the edges of the plot. Secure each of the four arms of the ConMod by hammering a ground staple through the mesh and into the ground (figs. 11, 12).

\section{Pitting Treatment}

Eight plots per site receive pitting treatments, with four pits dug in each plot before seeding occurs. In each quadrant of the plot, dig a pit that is roughly $40 \times 40 \mathrm{~cm}$ and $10 \mathrm{~cm}$ deep (fig. 13). The pits should be square, evenly spaced, and take up a similar amount of area as ConMods. Pits can be dug with McLeods, shovels, or mattocks. Scrape the O-horizon or first few centimeters of topsoil to a pile to the side before digging the pit. The bottom of the pit should be flat, creating a level basin rather than a deep hole. Use the reserved topsoil to slightly backfill the pit to improve biological soil properties in the bottom of the pit. Spread any

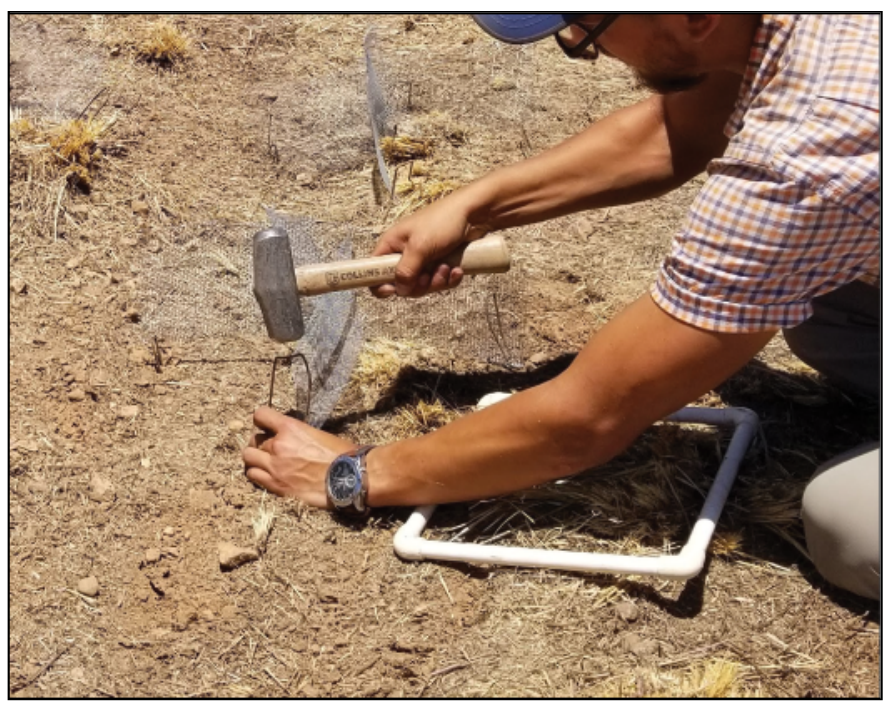

Figure 11. Photograph showing installation of one arm of a Connectivity Modifier (ConMod) with landscape staple.

remaining soil from the pit evenly around the surface of the plot (in space between pits).

\section{Mulch Treatment}

Woody mulch can be sourced from a variety of locations and should be designated "weed free". Eight plots per site receive mulch treatments following seeding. Fill a 5-gallon (19 liter [L])

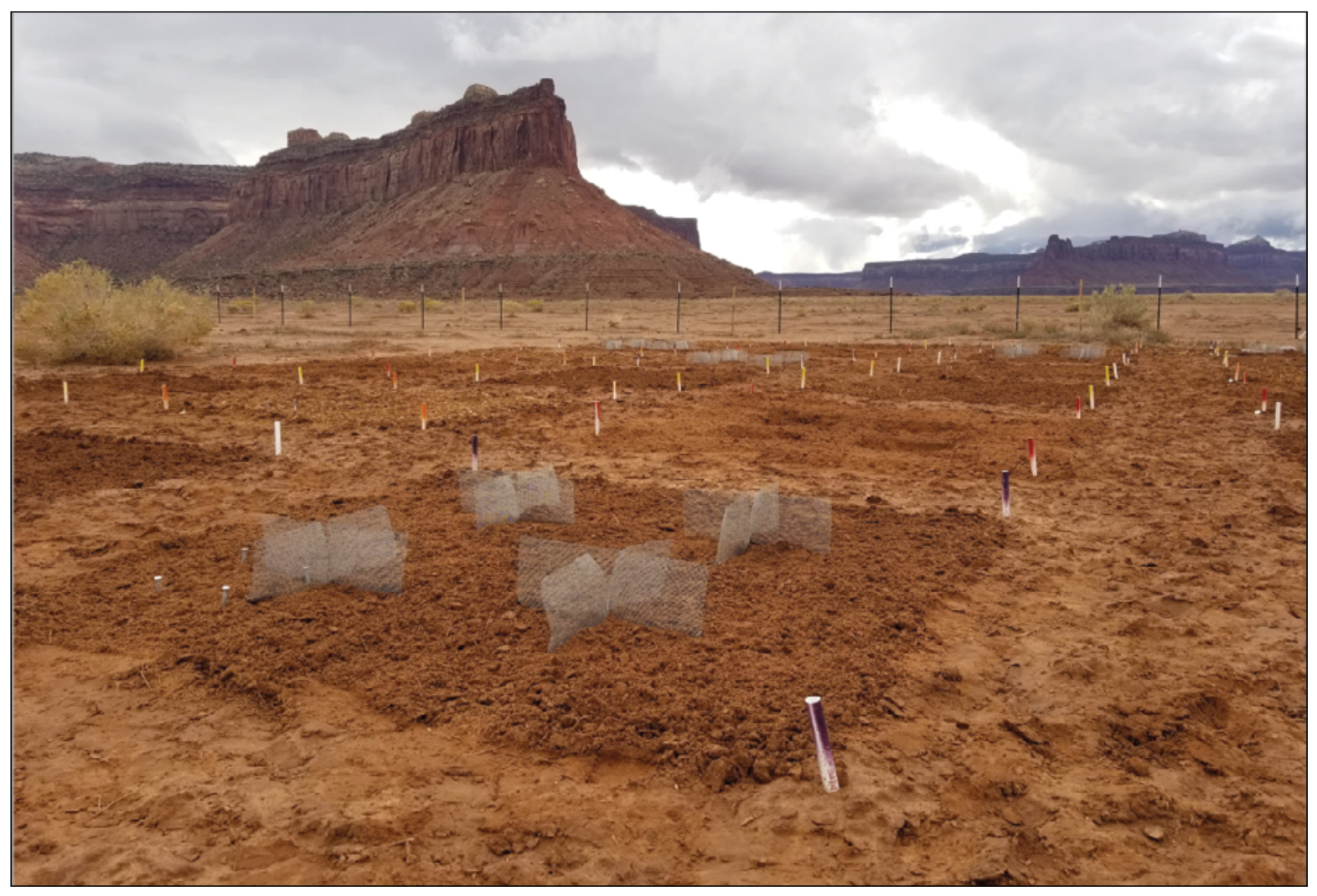

Figure 12. Photograph showing Connectivity Modifiers (ConMods) installed equidistant from edges of plot, with arms running parallel to edges. 
bucket with mulch (loosely, not compacted), and sprinkle it evenly by hand over the seeded plot (fig. 14).

\section{Reference Plots}

Install 16 reference plots to help identify seedlings of the species that are germinating and growing in the nearby study plots. A seedling photograph reference guide can also be developed based on the seedlings that emerge in these plots to assist with further identification.

At each site, lay out sixteen small $25 \times 25$-cm plots separated by at least $50 \mathrm{~cm}$. Prepare the plots similarly to the pitting treatment plots to ensure high seedling recruitment (fig. 15). Dig each plot out to a depth of about $10 \mathrm{~cm}$ with a mattock or shovel and spread excess soil outside the plot to reduce backfilling. Mark at least two opposite corners of the plot with nails. Label each plot with a marker identifying the species that was seeded. Hand broadcast a single species into the labeled plot, using one pre-weighed packet of seed per plot. Cover seeds with a light layer of loose soil to help prevent seeds from blowing away and tamp down the soil.

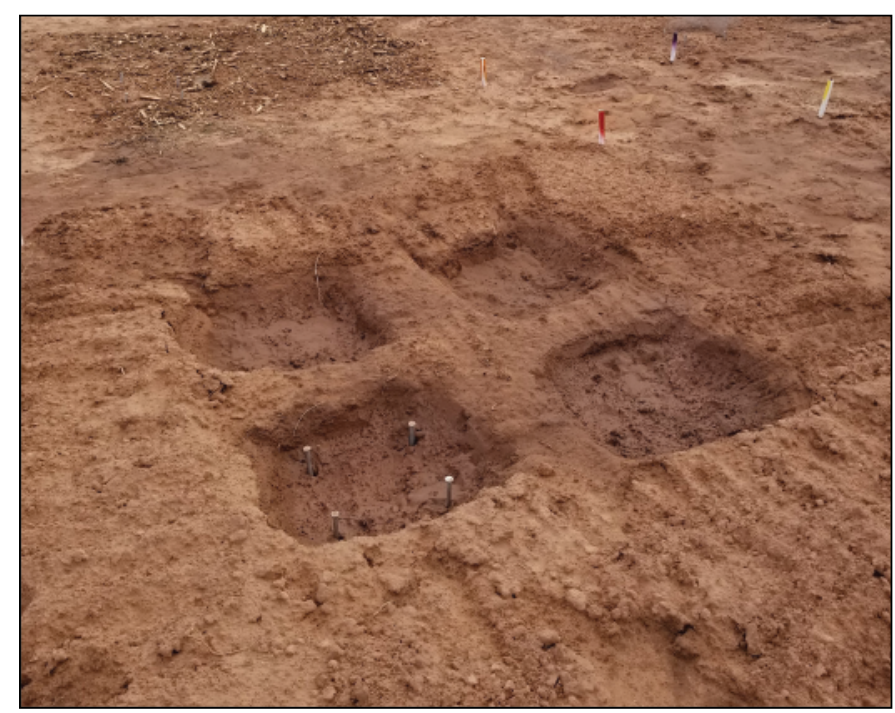

Figure 13. Photograph showing four pits in a plot, with nails marking the pit that will be used for monitoring.

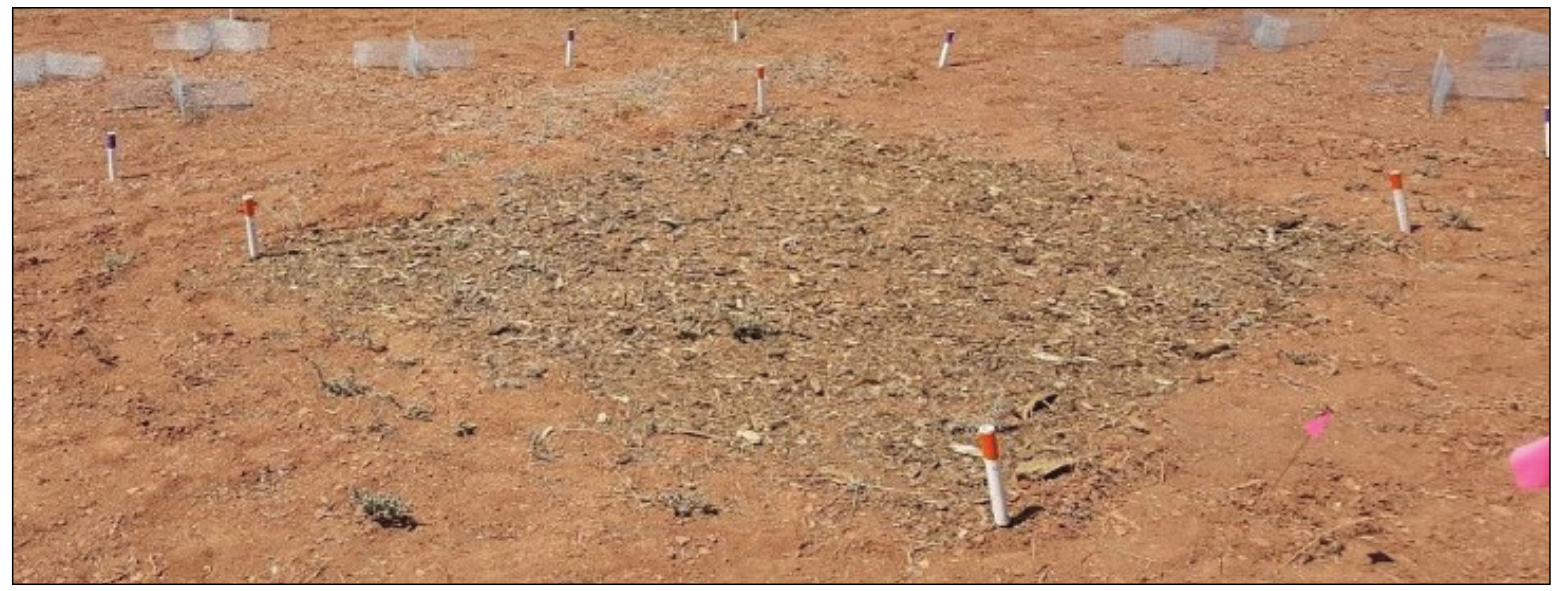

Figure 14. Photograph showing mulch treatment at a RestoreNet plot with seeds broadcasted by hand.

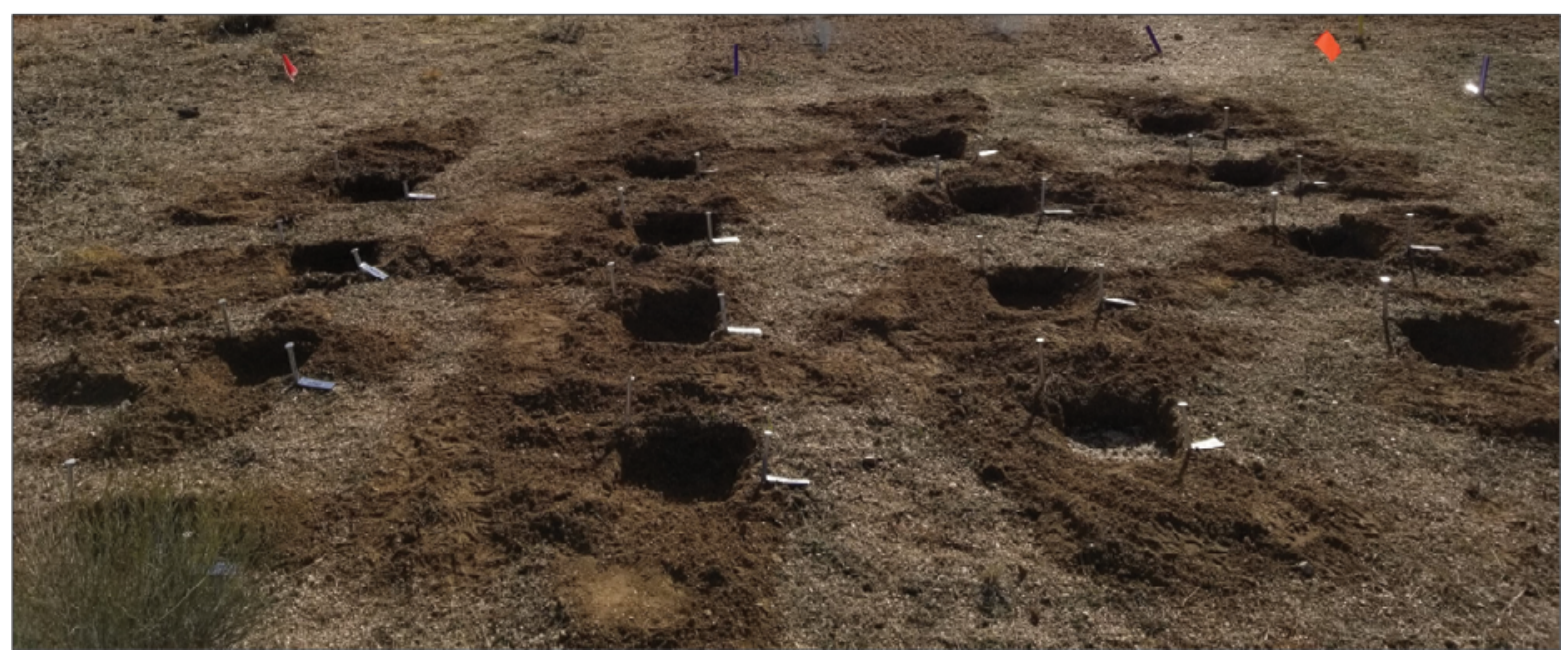

Figure 15. Photograph showing reference plots placed adjacent to experimental plots and marked with nails at two corners with a label on each plot. 


\section{Monitoring Subplot Installation}

Monitoring seedling treatments is done at the subplot level, which is a smaller area within each of the $2 \times 2$-m treatment plots. The subplot markers should be installed after seeding and before seedlings begin to emerge. Subplots are $25 \times 25 \mathrm{~cm}$ and located in the northeast corner of plots. To install, make a $25 \times 25$-cm quadrat out of PVC pipe (fig. $16 A$ ). Each subplot will require four permanent corner markers: ideally $20-25$-cm spike nails, pounded into the interior corner of the quadrat so that the nails stick up a few centimeters above the plot. For the pitting treatment, be sure the nails stick up above the top of the pit in case the pit fills in with sediment.

For plots with pits, place the subplot directly in the northeast pit of the plot (fig. 13). For plots with ConMods, place the subplot into the northeast quadrant of the northeast ConMod, so that one of the corners of the subplot is as close to the center of the ConMod as possible (fig. 16B). For plots with mulch, seed-only plots, and control plots, place the subplot in the northeast corner, $40 \mathrm{~cm}$ from the plot edges (fig. 16C).

\section{Outplanted-Seedling Experiment}

The optional outplanted-seedling experiment aims to test whether transplanting container-grown plants from a greenhouse can influence re-vegetation success. This experiment contains two types of plots: monoculture (all individuals planted are of the same species) and polyculture (individuals planted are of more than one species). The outplanted-seedling experiment of RestoreNet is also designed to evaluate if restoration success and recovering ecosystem properties are a function of plant functional traits. Evaluation of functional traits will aid in determining which growth strategies improve ecosystem recovery in different environmental contexts. More information on obtaining functional trait data using a greenhouse grow-out can be supplied upon request.

At each site, the outplanted-seedling experiment has thirty-six $2 \times 2$-m plots: 4 controls ( 2 with no plants, 2 with dead plugs), 16 monoculture plots (one plot for each species), and 16 polyculture plots (where each species occurs in 4 plots). Each plot

$\boldsymbol{A}$

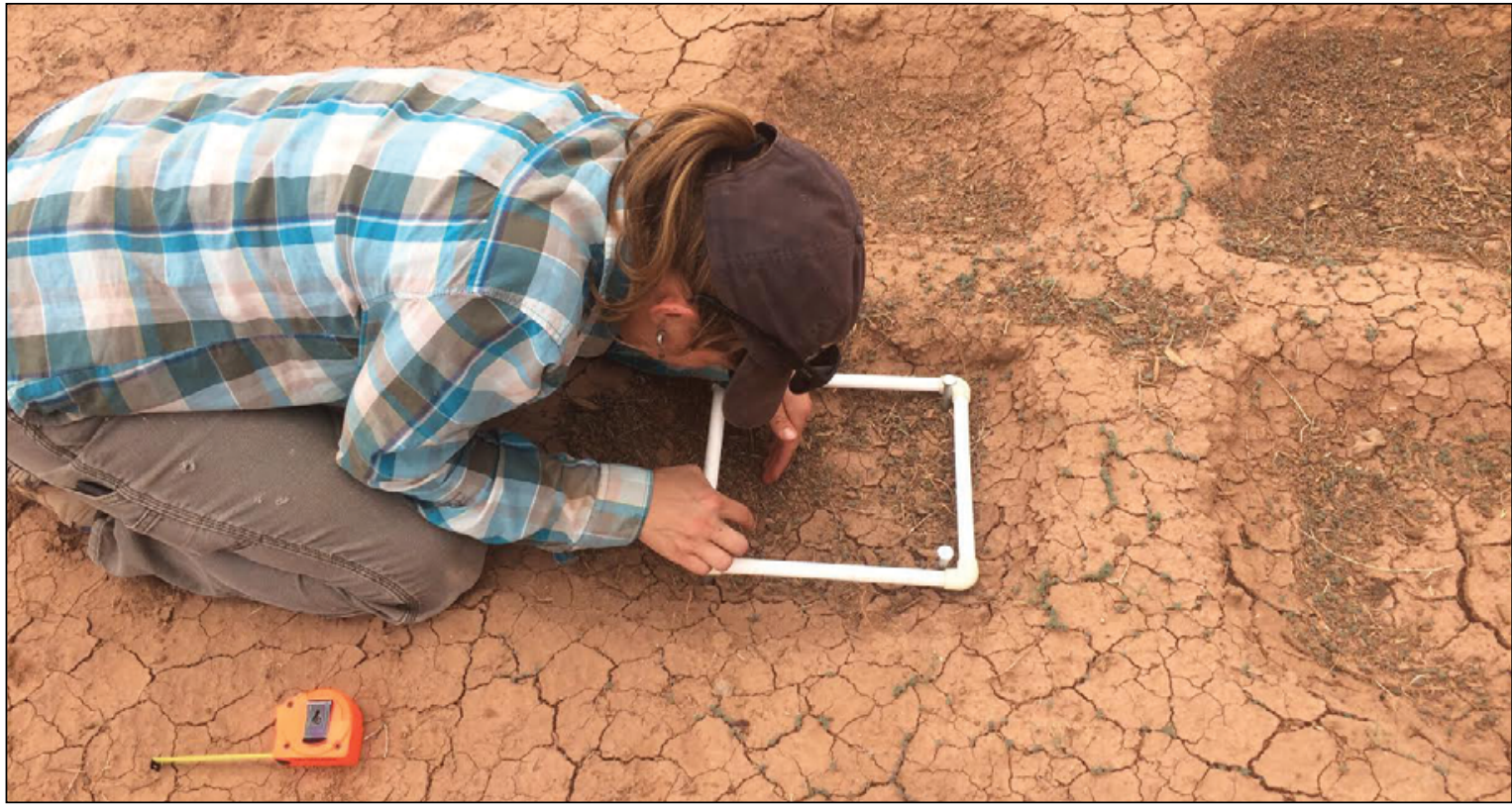

B

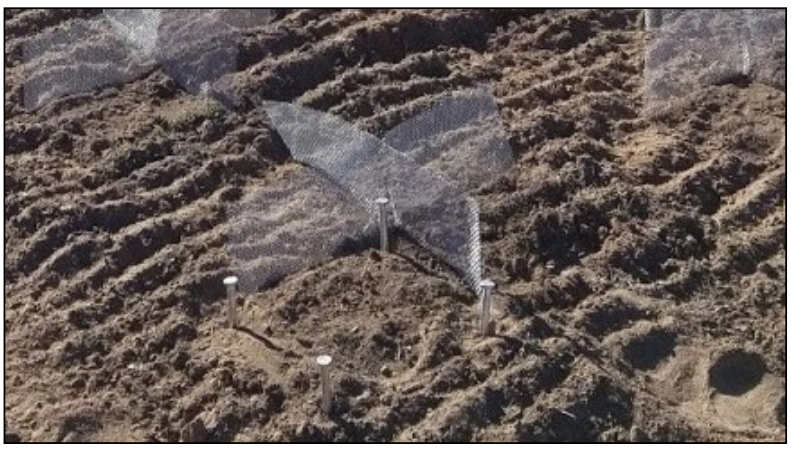

C

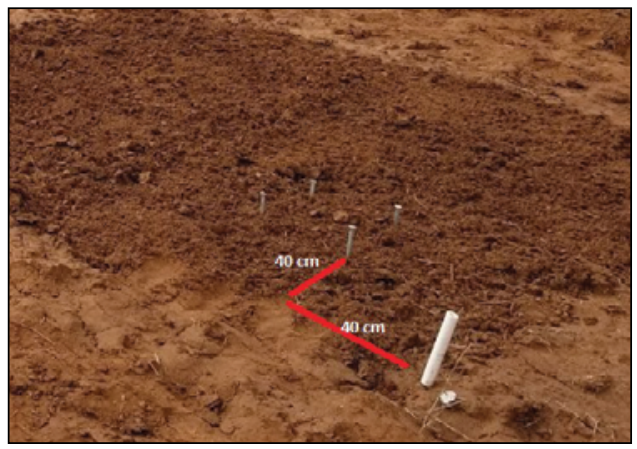

Figure 16. Photographs showing subplot installations. $A$, Monitoring of a subplot quadrat inside a pit. $B$, Subplot for seedling monitoring installed in the northeast corner of a ConMod plot. $C$, Subplots installed $40 \mathrm{~cm}$ from the edge for mulch, seed-only, and control plots. 
has 36 seedlings planted in a $6 \times 6$-seedling grid. Every species requires 36 seedlings for monoculture sites and 36 seedlings to be used across the polyculture site for a total of 72 individuals.

\section{Greenhouse Protocol}

Plants should be started in a greenhouse 3 to 5 months before projected outplanting date. This does not include time needed for seed treatments, which can take 30 to 60 additional days. For a list of seed treatments previously used on RestoreNet species, see appendix 4.

\section{Quantities}

Each species is represented by 72 individual plants, but to ensure this number survives, the best practice is to plant a minimum of 100 individuals of each species in case there is mortality. Plant more than 100 individuals for species with known low germination rates or for seeds that were wild collected, as farmed seeds tend to have more reliable uniform germination.

\section{Potting Mix}

Depending on the size of container used to grow the plants, approximately 3 cubic meters $\left(\mathrm{m}^{3}\right)$ of potting mix is needed. The standard mix is one part sphagnum peat moss, one part vermiculite, and one part perlite. Coconut coir can be substituted for peat moss.

\section{General Growing Protocols}

Use the following protocols for general growing:

- Research and perform any necessary treatments to improve seed germination (for example, cold stratification). Some of these treatments may take 30 to 60 days, so leave enough time for their implementation. See appendix 4 for seed treatment information for RestoreNet species currently being used in the outplanted-seedling experiment.

- Thoroughly incorporate all potting mix ingredients. Slowly wet and mix so the potting mix is uniformly wet to the level of a moist sponge: not dripping when squeezed, but thoroughly moistened. Fill the pots with the potting mix, tap on the ground to settle the mix, and top off with more potting mix to within $3 \mathrm{~cm}$ of the top of the cone, which leaves enough room for watering. Do not overfill.

- Seed by first making a divot in the potting mix, placing a seed in it, and covering it with soil. Some small seeds can be placed on the top and sprinkled with some sand or vermiculite. Follow the general rule of sowing 1.5 times deeper than the width of the seed.

- Sow one extra tray of grass to be used as a control - any reliable species will do. This tray will be sprayed with herbicide just before planting.
- Water trays 1 to 2 times a day, depending on greenhouse conditions. Water gently at first with a fine mist sprayer so seeds don't wash out of the pots. Water more deeply as plants grow and establish roots.

- After germination, thin pots by pulling extra seedlings so that each pot contains only one plant. Grass species are an exception for which many seedlings per container is desired.

- Use liquid fertilizer at 30 parts per million of 20 percent nitrogen, 20 percent phosphorus, and 20 percent potassium (20-20-20 NPK) after true leaves appear. Apply two times a week during watering, being sure to rinse the plants with fresh water before and after fertilizer to prevent leaf burn. Stop fertilizing and leach fertilizer from pots before hardening off.

- Harden off the plants for 2 weeks or longer before outplanting by placing them under a shade structure outside.

\section{Planting Layout Design}

Follow these recommendations in designing a planting layout:

- Prior to planting, randomize the plant layout within each polyculture plot using the Outplanting Pattern Layout in appendix 9.

- Assign a PVC-pipe color marking for each plot that designates the type of plot assemblage: blue is polyculture, green is monoculture, and black is control (fig. 9).

\section{Field Planting Protocol}

Use the following protocol for field planting (shown in fig. 17):

- Transport plants from the greenhouse to the site. Consider bringing the plants to the site the day before planting with a large group of people, depending on transportation arrangements. Plants can sit out in trays overnight at sites if they are protected inside the fenced area (as applicable) and if the temperatures do not drop below freezing overnight. For plants sitting out at the site for multiple days during planting, be sure to water them 1 to 3 times a day as needed. Consider erecting a shade tent over the plants in areas with harsh sun, so that the roots don't burn.

- For the control seedlings, spray these with herbicide $(\sim 3$ percent glyphosate, or more concentrated if necessary) at the beginning of the planting week, ideally 1 to 2 days before planting. If possible, plant the dead seedling controls last to avoid any accidental transfer of herbicide to treatment seedlings. Plant the dead seedling control plots following the same protocol as the treatment plots, and water them the same amount. 


\section{A. Bore holes in $6 \times 6$ pattern}

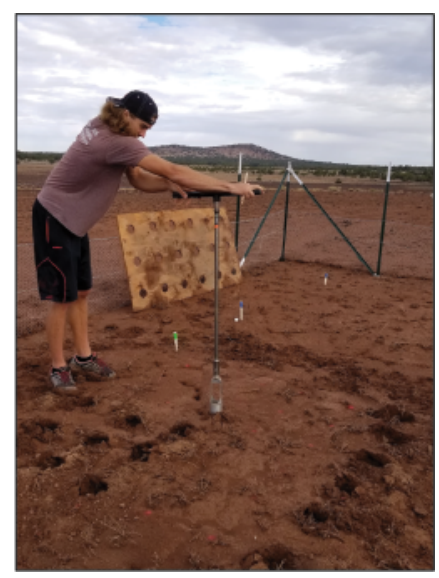

E. Let water soak, then plant

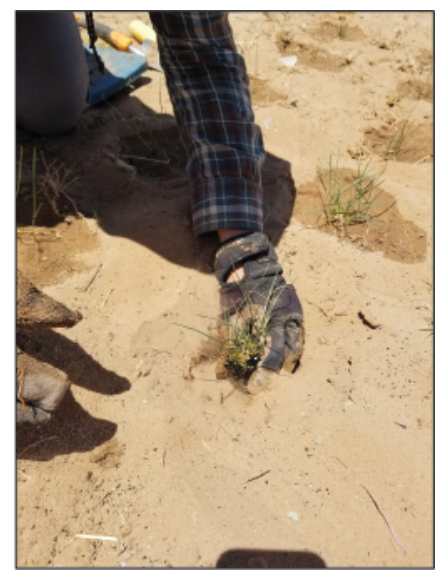

B. Clear out loose soil from hole

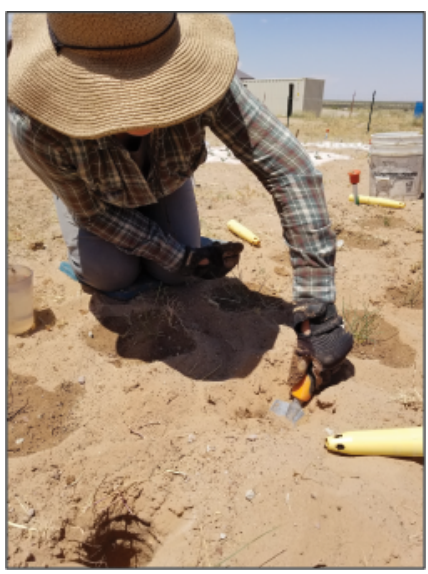

F. Press soil firmly around plug

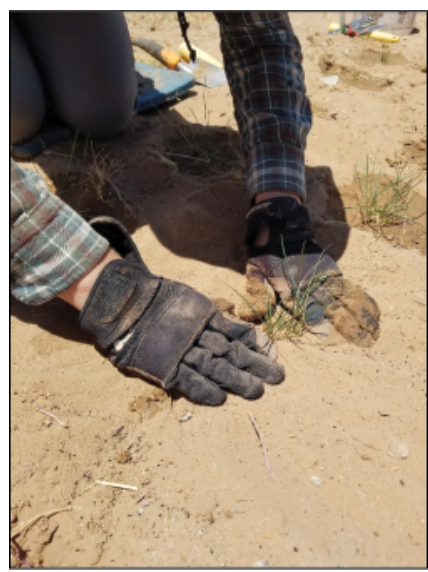

C. Add 0.75 liters of water

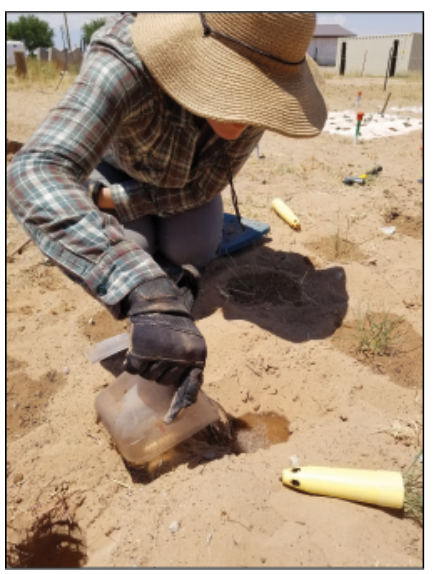

G. Create berm around seedling

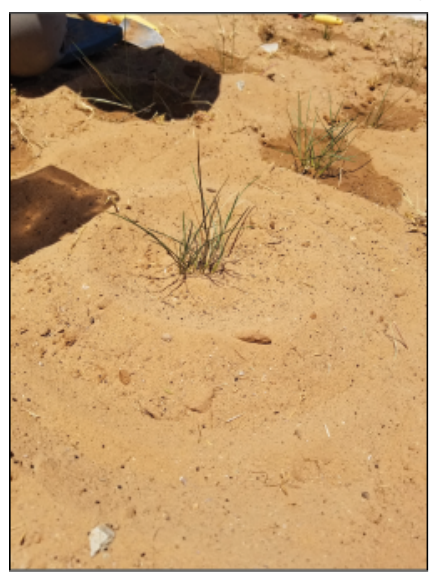

D. Remove plug from cone

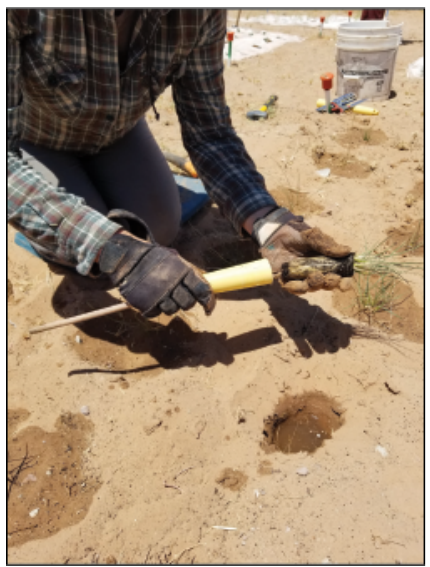

\section{H. Add 0.25 liters of water}

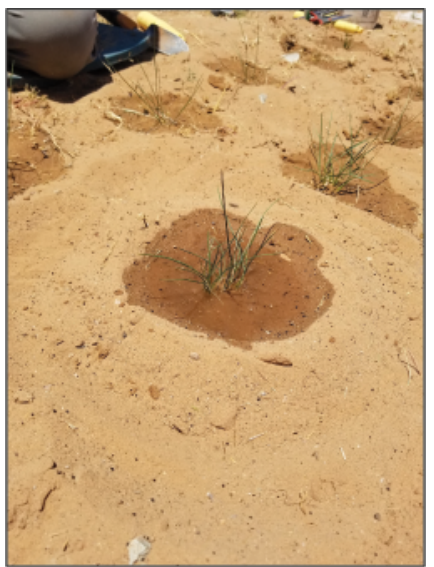

Figure 17. Photographs showing steps for site preparation and planting seedlings $(A-H)$.

- To begin the transplanting process, mark planting locations about $30 \mathrm{~cm}$ apart within a plot. Create a template out of plywood or cardboard for this purpose. Mark the soil for each seedling hole with either a visual marker (such as a dot of spray paint) or a physical marker (such as a garden staple), then remove the template.

- Use a hand or power auger to bore holes at each marked spot, placing the removed dirt in a pile next to the hole, if possible. Bore holes to the depth of the seedlings' pots, typically about $13 \mathrm{~cm}$.

- Once the holes have been bored, they typically need to be redefined and cleared of all dirt with a hand trowel to ensure the entire seedling plug will fit. After handclearing, pour $0.75 \mathrm{~L}$ of water into each hole, using a basic measuring cup. Depending on the site and soil conditions, the water may take up to 30 minutes to soak in well enough to plant. In this case, bore and water multiple holes before returning to plant them after water has soaked into the soil. Some sites may absorb the water rapidly and plants should be installed quickly so that the soil in the hole doesn't dry out.
- Set seedling plugs next to the holes to ensure an accurate plot layout. To plant a seedling, remove it from its pot or cone-tainer using a dowel or stick to gently push out all roots and soil from underneath or tapping the side of the pot to release all matter. If the soil and roots fall apart while being removed, place all pieces of soil and root into the hole, so that each planting receives the same amount of greenhouse material.

- Place the plant into the hole, so that the top of the plug is at or just below ground level. Gently pack in soil around the plug, and firmly push down on the top of the soil once the plug is completely buried to remove any air pockets around the roots. Using surrounding soil, create a small berm of dirt around the plant, so that the plant is sitting in a small indentation. Add $0.25 \mathrm{~L}$ of water to the newly planted seedling.

- Each site should have 4 control plots: 2 with no plugs and 2 with dead seedlings. For the no-plug controls, use the plot template to mark and auger holes in order to create the same level of disturbance to the soil as treatment plots, 
but simply repack the removed soil without adding any plants or other material. No-plug controls do not need to be watered.

- After planting, seedlings may need to be watered to increase success of initial survival, depending on local precipitation. Water every 2 weeks, in hot and dry conditions, by applying $0.25-0.5 \mathrm{~L}$ of water to each seedlings' berm by hand, using a measuring cup, for maximum local infiltration. Seedlings should ideally not be watered after 2 months of planting, at which point their survival will depend on local conditions.

\section{Monitoring Protocol}

The purpose of this protocol is to track seedling emergence and plant establishment within plots that are part of the restoration field trial network. The protocol outlines procedures to identify seedlings and monitor their establishment and growth. (See appendix 8 for the monitoring data sheet.)

\section{Seeded Plots}

Seeded plots will need to be monitored at a minimum twice a year in late spring (May) and early fall (SeptemberOctober). Optional additional monitoring of germinating seedlings includes visits twice a month during the growing season to track individual seedlings' germination and survival. Monitoring includes taking photographs, tracking any live plants within a subplot, and recording the canopy cover of seeded and unseeded species at the plot level.

\section{Equipment}

- Camera (to take seedling photographs)

- Site map

- Pencil

- Data sheets and clipboard

- Resealable plastic bags or plant press (to collect unknown plants outside of plots)

- Metric tape measure/ruler

- Seedling species identification pictures, including information on which species are in each seed mix

- Copies of data sheets from previous visits (not originals)

- Cardboard or plexiglass cut-outs to assist with ocular cover estimates (if needed)

- Oil for rain gage maintenance (if needed)

\section{Procedure}

\section{Photographs}

- On the first monitoring visit, establish a photograph point for the entire site, or as many of the plots as possible. This may be from the fence gate or from a corner of the site. If possible, install an additional T-post or stake for the photograph location. Note where the photograph point is located and what angle the photograph was taken (for example, due north or $30^{\circ}$ ), replicating the same location and angle for each visit.

- Take representative photographs of plots of each treatment type.

- Curate photographs on the RestoreNet SharePoint site in a folder named with date and location.

\section{Rain Gage}

- If using a rain gage at the site, record the level of water in the rain gage to the nearest centimeter.

- Discard water and oil in the rain gage and refill with a thin layer of fresh oil to reduce evaporation of precipitation between visits.

- Record precipitation on the data sheet and later transfer it to the digital spreadsheet.

\section{Reference Plots}

- Inspect reference plots and record the seeded species established. Look at the characteristics of the seedlings, noting any differences between similar-looking species. This may help with species identification in plots.

\section{$25 \times 25-\mathrm{cm}$ Subplots}

- Find the $25 \times 25-\mathrm{cm}$ subplot in each plot, which is marked by nails at the corners and located in the northeast corner of the larger $2 \times 2-\mathrm{m}$ plot.

- Identify the species (or the highest level of identification possible) of each individual within the subplot. If available, use reference plots seeded at the site or a seedling guide for identification of seedlings. Add a new row on the data sheet for each new species encountered; subplot data take up multiple rows of the data sheet. For each species, use the USDA species code (for example, SPCR for Sporobolus cryptandrus, using the USDA Plants Database, https://plants.usda.gov). For unknown species, use and define a code that can consistently be used for the individual on future visits (for example, UNFO1 for Unknown Forb 1). Define all new codes in the "Species notes" column of the data sheet by writing 
out the full name of the species. Refer to the data sheet from the previous visit to maintain continuity of seedling identification codes. Note that unknown species may become known once they have reached a later stage of growth. Record any species identification changes in the "Species notes" column of the data sheet (for example, "UNGR2 now positively identified as BOGR").

- In each species row, record whether the species is seeded or not (or provide best guess), by writing YES or NO in the "Species Seeded" column. It can help to take an informal survey of seedlings in the area outside of the plots to help identify if a seedling is seeded; if it doesn't occur outside of the plot, it might be seeded. However, it is better to err on the side of new small unidentified seedlings being marked as "unseeded" since unseeded species often respond positively to the additional treatments inside the plots.

- Count the number of individuals of the species within the subplot, and the average height of individuals in millimeters, using a tape measure or ruler. Measure multiple individuals and average the height if they are not all the same. Record the functional group of the species (grass, forb, or shrub). Individuals should only be counted if they are rooted within the subplot, which is delineated by the outermost edge of the nails (fig. 18).

- Record the confidence of the species identification, on a scale of 1 to 3 (1, low certainty; 2 , medium certainty; 3 , high certainty). Unknown species will be marked as N/A.

- Take a photograph of unknown species and record the photograph number on the data sheet or digitally label the photograph for later identification. If possible, collect unknown species from outside the plots to identify in the lab. Curate these photographs in a folder on the SharePoint site with the date, location, and plant code.

- If there are more species in the plot than there are rows on the data sheet, use the subsequent plot section on the data sheet, but be sure to make clear notation that the two plot sections are being used for one plot.

\section{Individual 2×2-m Plots}

\section{Canopy Cover Measurements}

- Before conducting canopy cover estimates, calibrate personal estimates with all individuals performing monitoring. Each person should independently decide what cover percentage they would give a plot, and then share with the other observers. Continue making practice estimates, adjusting percentages so that all estimates made are within 5 percent of each other. Use the canopy cover estimate guide to start (fig. 19).

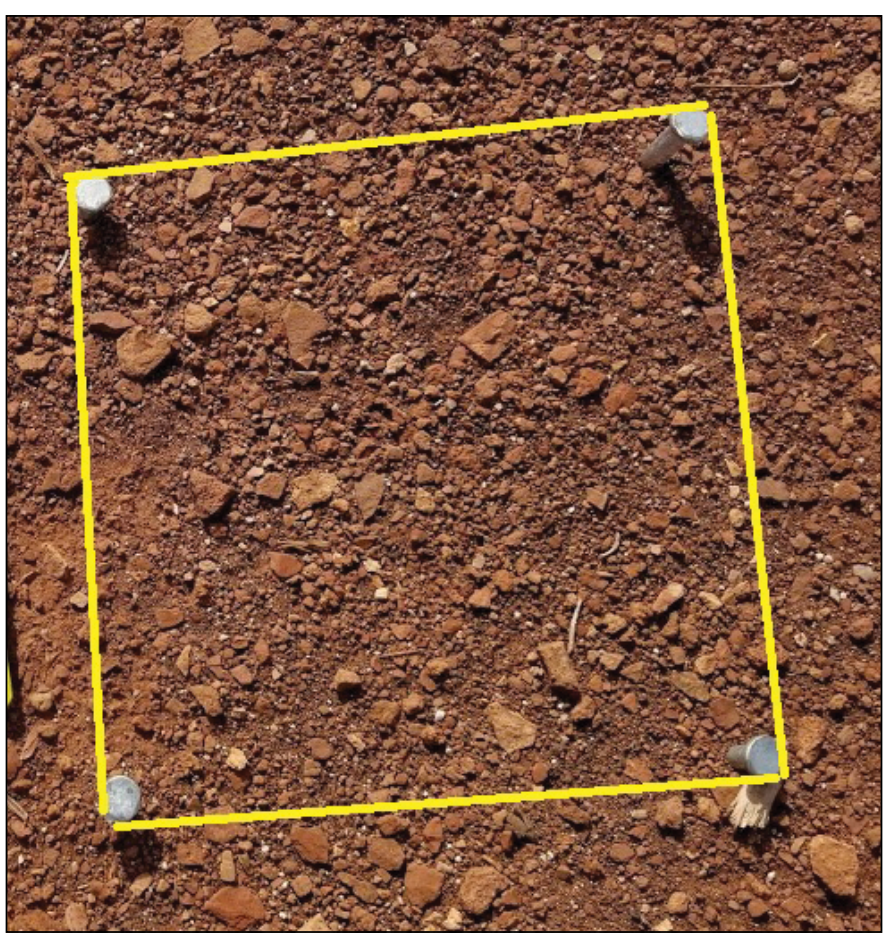

Figure 18. Photograph showing the monitoring area marked by nails. Yellow line designates the area to be monitored; any plants rooted inside this boundary should be counted.

- If possible, bring a $20 \times 20$-cm cut-out of cardboard or plexiglass, to help visualize a 1 percent cover estimate of each plot. This area is also just smaller than the subplot or $0.4 \mathrm{~m}^{2}$.

- Make a visual estimate of total seeded plant canopy cover (1 percent, 15 percent, and so on) throughout each $2 \times 2-\mathrm{m}$ plot. If the cover is less than 1 percent, record it as "TR" for "trace." Use best judgment and reference plots (if available) to determine which seedlings are most likely from the seeded species mix.

- Make a visual estimate of total plant canopy cover in each plot (including seeded species and unseeded/weed species). If the cover is less than 1 percent, record it as "TR" for "trace".

Notes

See figure 20 for an example of data collected at each plot.

- If species are present throughout the $2 \times 2$-m plot, but not present within the subplot, write down those species in the notes section, so that the makeup of the plot canopy cover can be later deduced.

- Record any notes about the plots or subplots, abbreviations used (for example, SATR = Salsola tragus), or useful information about the species identity (for example, 
Figure 19. Diagram showing guide for estimating percentage cover.

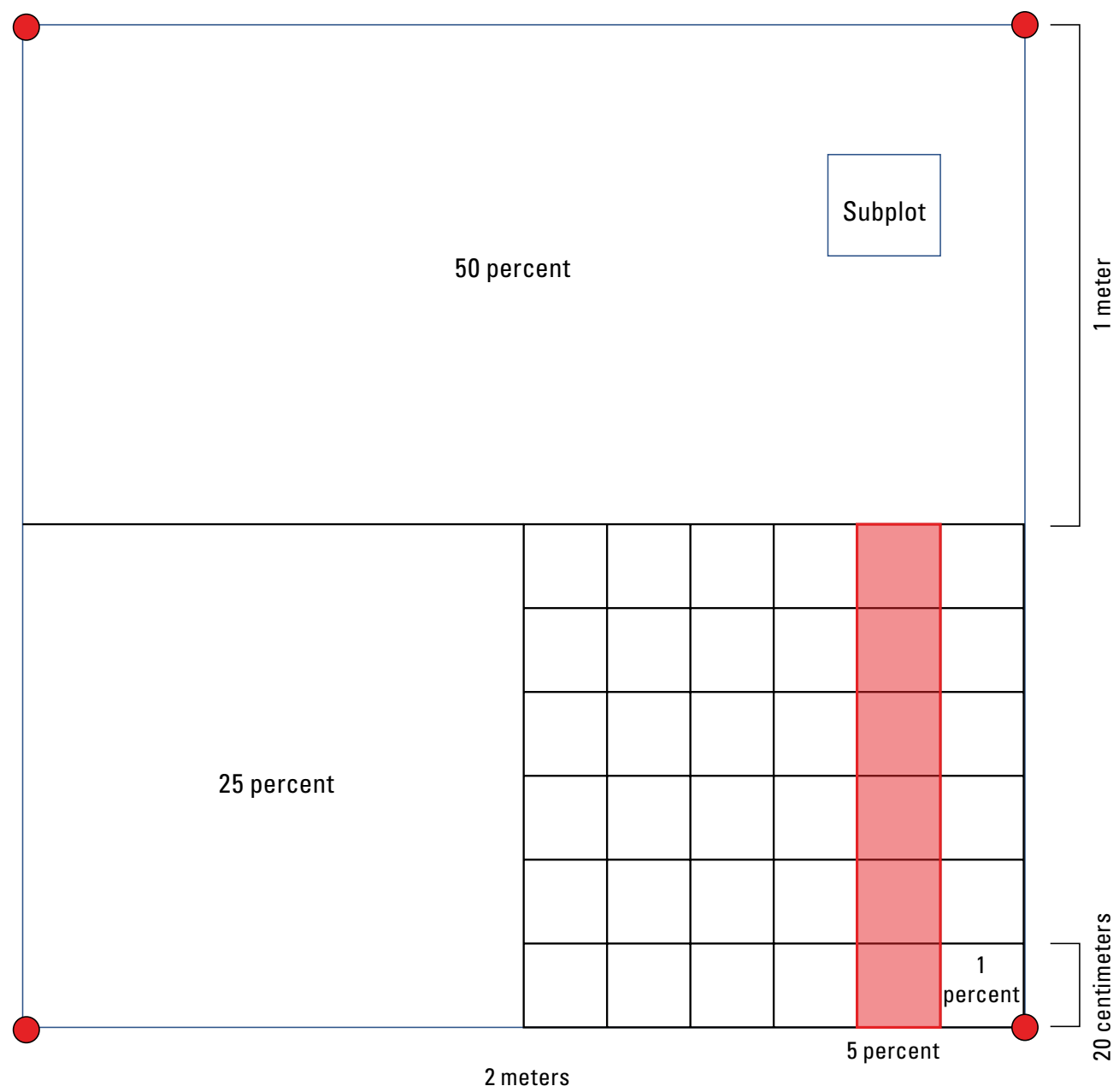

RestoreNet Monitoring Datasheet

Site:

Observer(s):

Rain gage amount (inches to 2 decimal places):
Date:

Recorder: Dumped water?

Time:

Page of

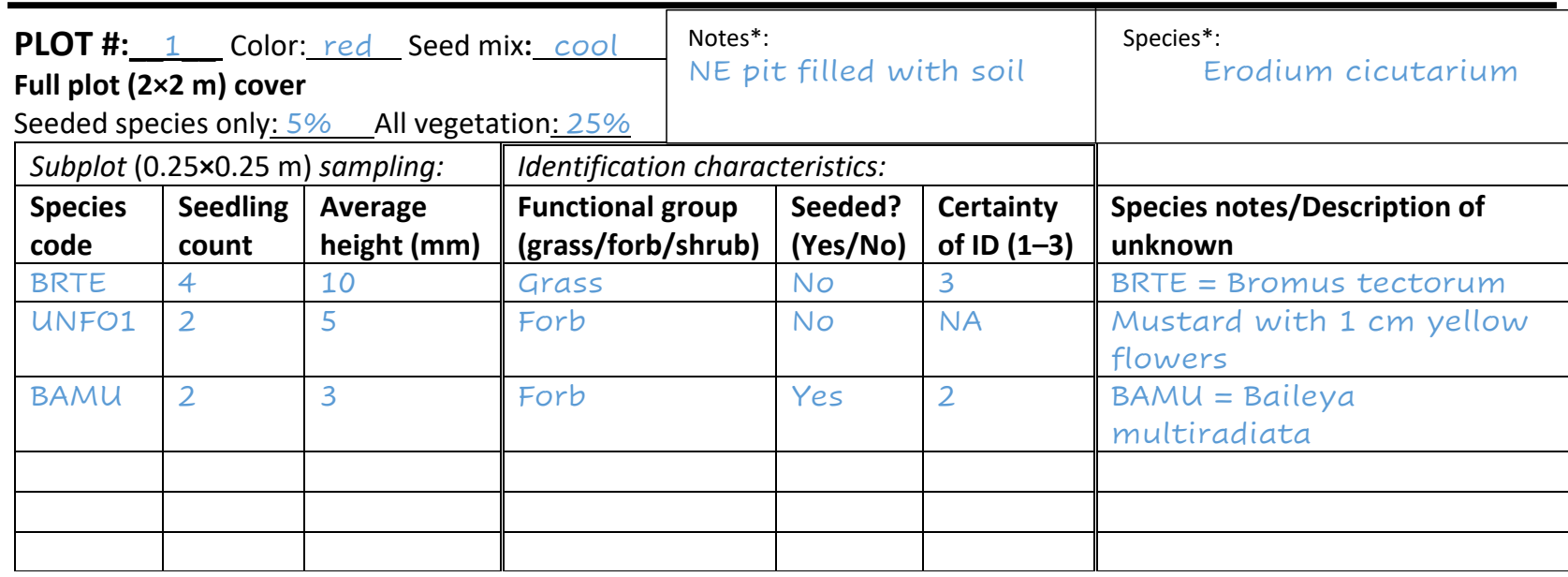

Figure 20. Data sheet example showing information collected at each plot. NE, northeast; \%, percent; NA, not applicable. 
UNFO1 has red stem and fascicled leaves) in the "Species notes" column of the data sheet.

Important notes to record for different types of treatments include the following:

- The percentage of mulch in plots and in subplots

- The percentage of a pit that has filled with soil or shows erosion (draw diagram)

- If sediment is trapped by a ConMod

- If the plot has signs of erosion or other disturbance

\section{Outplanted-Seedling Experiment Plots}

Monitoring for the outplanted seedlings includes recording survival of individuals and average height and widths of each species (fig. 21). An individual is considered alive if it had new leaf tissue and (or) increase in height or width at any point throughout the growing season. Monitoring occurs at the same time as the seeded plots (late spring and early fall). Create data sheets for each plot with the plant species code listed. Be sure to mark on the data sheet which corner of the plot has the tag (see appendix 9 for details on plot layout.)

\section{Data Curation}

Data is curated on the RestoreNet SharePoint site. Use the following steps for curation of photographs and data sheets:

1. Request access to the SharePoint site at this URL: www. doimspp.sharepoint.com/sites/usgs-sbsc-ramps-restorenet.

\begin{tabular}{|l|l|l|l|l|l|l|l|l|l|l|l|}
\hline \multicolumn{1}{|l|}{ Plot \#2 } & & & & & & \\
\hline BOCU & w: & BOCU & w: & ASTU & w: & ASTU & w: & PLMU & w: & PLMU & w: \\
\hline h: & w: & h: & w: & h: & w: & h: & w: & h: & w: & h: & w: \\
\hline BOCU & w: & PLMU & w: & MATA & w: & PLMU & w: & BOCU & w: & MATA & w: \\
\hline h: & w: & h: & w: & h: & w: & h: & w: & h: & w: & h: & w: \\
\hline BOCU & w: & BOCU & w: & PLMU & w: & PLMU & w: & ASTU & w: & MATA & w: \\
\hline h: & w: & h: & w: & h: & w: & h: & w: & h: & w: & h: & w: \\
\hline MATA & w: & MATA & w: & BOCU & w: & ASTU & w: & ASTU & w: & MATA & w: \\
\hline h: & w: & h: & w: & h: & w: & h: & w: & h: & w: & h: & w: \\
\hline PLMU & w: & MATA & w: & ASTU & w: & BOCU & w: & MATA & w: & BOCU & w: \\
\hline h: & w: & h: & w: & h: & w: & h: & w: & h: & w: & h: & w: \\
\hline Comments: & w: & ASTU & w: & PLMU & w: & MATA & w: & ASTU & w: & ASTU & w: \\
\hline
\end{tabular}

Figure 21. Data sheet example for the outplanted-seedling experiment, showing a single plot with species 4-letter code and space for plant heights and widths. 
Access requires obtaining permission and creating a username and password.

2. Within the "Site Specific Data" folder, each RestoreNet region has a separate folder containing individual folders for photographs, raw data, and general site information. After each site visit, add photographs to the appropriate folder with photograph titles that include the site name, visit date, and description (for example, FlyingM_May2021 SitefromNWcorner).

3. Within the photograph folder for your region and site, add photographs of unknown plants and seedlings. Use the photographs to make a guide for identifying seedlings and labeling unknown seedlings. These guides will help keep data collection and nomenclature consistent for future monitoring.

4. Make at least two copies of data monitoring sheets. Keep one copy as part of the permanent data records and include the other with the monitoring packet to be referenced during upcoming monitoring visits. Digitally scan the data sheets and upload them to the SharePoint folder.

5. Enter data into an Excel spreadsheet, following the instructions found at the RestoreNet SharePoint site.

\section{Summary}

The RestoreNet experiment is a networked ecological experiment that spans dryland ecosystems. It leverages expertise from researchers, land managers, and restoration practitioners to build knowledge, improve techniques, and ultimately improve the condition of the land. By co-producing science in a systematic way across an ecological gradient and leaving space for future scientific inquiry and collaborations, RestoreNet creates replicable, scalable solutions to some of the toughest problems in public and private land management both today and for years to come. This protocol enables partners who want to join the network and make meaningful contributions to the field of ecological restoration in drylands.

\section{Selected References}

Bainbridge, D., 2007, A guide for desert and dryland restorationnew hope for arid lands, society for ecological restoration (the science and practice of ecological restoration series): Washington D.C., Island Press, 416 p.

Butterfield, B.J., 2015, Environmental filtering increases in intensity at both ends of climatic gradients, though driven by different factors, across woody vegetation types of the southwest USA: Oikos, v. 124, no. 10, p. 1374-1382, https://doi.org/10.1111/oik.02311.
Butterfield, B.J., and Munson, S.M, 2016, Temperature is better than precipitation as a predictor of plant community assembly across a dryland region: Journal of Vegetation Science, v. 27, no. 5, p. 938-947, https://doi.org/10.1111/ jvs. 12440 .

Chambers, J.C., 2000, Seed movements and seedling fates in disturbed sagebrush steppe ecosystemsimplications for restoration: Ecological Applications, v. 10 , no. 5 , p. 1400-1413, https://doi.org/10.1890/10510761(2000)010[1400:SMASFI]2.0.CO;2.

Doherty, K.D., Butterfield, B.J. and Wood, T.E., 2017, Matching seed to site by climate similarity: techniques to prioritize plant materials development and use in restoration: Ecological Applications, v. 27, no. 3, p. 10101023, https://doi.org/10.1002/eap.1505.

Havens, K., Vitt, P., Still, S., Kramer, A.T., Fant, J.B., and Schatz, K., 2015, seed sourcing for restoration in an era of climate change: Natural Areas Journal, v. 35, no. 1, p. 122-133, https:// doi.org/10.3375/043.035.0116.

James, J.J., Svejcar, T.J., and Rinella, M.J., 2011, Demographic processes limiting seedling recruitment in arid grassland restoration: Journal of Applied Ecology, v. 48 , no. 4, p. $961-969$, https://doi.org/10.1111/j.13652664.2011.02009.x.

Larson, J.E., Sheley, R.L., Hardegree, S.P., Doescher, P.S., and James, J.J., 2015, Seed and seedling traits affecting critical life stage transitions and recruitment outcomes in dryland grasses: Journal of Applied Ecology, v. 52, no. 1, p. 199209, https://doi.org/10.1111/1365-2664.12350.

Intergovernmental Panel on Climate Change [IPCC] (MassonDelmotte, V., Zhai, P., Pörtner, H.-O., Roberts, D., Skea, J., Shukla, P.R., Pirani, A., Moufouma-Okia, W., Péan, C., Pidcock, R., Connors, S., Matthews, J.B.R., Chen, Y., Zhou, X., Gomis, M.I., Lonnoy, E., Maycock, T., Tignor, M., and Waterfield, T., eds.), 2018, Global warming of $1.5^{\circ} \mathrm{C}$ - An IPCC Special Report on the impacts of global warming of $1.5^{\circ} \mathrm{C}$ above pre-industrial levels and related global greenhouse gas emission pathways, in the context of strengthening the global response to the threat of climate change, sustainable development, and efforts to eradicate poverty: IPCC, IPCC Special Report, 616 p.

Millennium Ecosystem Assessment, 2005, Ecosystem and Human Well-Being-biodiversity sysnthesis biodiversity synthesis: Washington D.C., World Resources Institute, $137 \mathrm{p}$.

Okin, G.S., Heras, M.M.D.L., Saco, P.M., Throop, H.L., Vivoni, E.R., Parsons, A.J., and Peters, D.P., 2015, Connectivity in dryland landscapes - Shifting concepts of spatial interactions: Frontiers in Ecology and the Environment, v. 13, no. 1, p. 20-27, https://doi.org/10.1890/140163. 
Omernik, J.M., 1995, Ecoregions-A spatial framework for environmental management, in Davis, W.S., and Simon T.P., eds., Biological assessment and criteria - tools for water resource planning and decision making, Boca Raton, Florida, Lewis Publishers, p. 49-62, https://doi.org/10.13140/ RG.2.1.4916.2726.

Seager, R., Ting, M., Held, I., Kushnir, Y., Lu, J., Vecchi, G., Huang, H.P., Harnik, N., Leetmaa, A., Lau, N.C. and Li, C., 2007, Model projections of an imminent transition to a more arid climate in southwestern North America: Science, v. 316 no. 5828, p.1181-1184, https://doi.org/10.1126/ science.1139601.

U.S. Department of Agriculture [USDA] Natural Resources Conservation Service, Butler, L.D., ed., 2003, National range and pasture handbook: Scotts Valley, California, CreateSpace, $214 \mathrm{p}$.

Woosley, A.I., 1980, Agricultural diversity in the prehistoric southwest: KIVA, v. 45, no. 4, p. 317-345, https://doi.org/10.10 80/00231940.1980.11757943. 
Appendixes 1-9 


\section{Protocol for Installing and Monitoring a RestoreNet Restoration Field Trial Network Site}

\section{Appendix 1. Seed Calculation Instructions}

Make a spreadsheet following this guide for calculating the amount of seed to acquire and seed at each plot.

Table 1.1. Seed weight calculations.

[Information in row 1 of columns A and B (see also gray shading) must be researched and entered for calculations. PLS, pure live seed]

\begin{tabular}{|c|c|c|c|c|c|c|c|}
\hline A & B & C & D & $E$ & $\mathbf{F}$ & G & H \\
\hline $\begin{array}{l}\text { Seeding rate } \\
\text { obtained from } \\
\text { seed vendors and } \\
\text { internet research } \\
\text { (upper threshold) } \\
\text { in pounds per acre }\end{array}$ & $\begin{array}{l}\text { Purity percentages } \\
\text { to decimals, } \\
\text { for example } 98 \\
\text { percent will be } \\
\text { entered as } 0.98\end{array}$ & $\begin{array}{l}\text { Adjusted seed } \\
\text { rate (pounds } \\
\text { per acre)/ } \\
\text { purity) }\end{array}$ & $\begin{array}{l}\text { Seed weight to be } \\
\text { applied to each } \\
\text { plot in ounces } \\
=\text { Column } \mathrm{C} \mathrm{x} \\
\text { ounce to pound } \\
\text { conversion } \\
(16) \times \text { acre to } \\
\text { plot conversion } \\
(.000988)\end{array}$ & $\begin{array}{l}\text { Number of plots } \\
\text { (16 at each site } \\
+2 \text { extra for } \\
\text { field reference) }\end{array}$ & $\begin{array}{l}\text { Total seed } \\
\text { weight in } \\
\text { pounds }\end{array}$ & $\begin{array}{l}\text { Total PLS } \\
\text { weight } \\
\text { needed } \\
\text { for project } \\
\text { (pounds) } \\
\text { with twice } \\
\text { the amount } \\
\text { in case of } \\
\text { re-seeding } \\
\text { and some } \\
\text { for gh starts }\end{array}$ & $\begin{array}{l}\text { PLS seeds to } \\
\text { purchase } \\
\text { (total weight in } \\
\text { pounds rounded } \\
\text { up) }\end{array}$ \\
\hline $\begin{array}{l}\text { Research seeding } \\
\text { rate for each } \\
\text { species }\end{array}$ & $\begin{array}{l}\text { Find on seed tag } \\
\text { after purchase } \\
\text { or do a viability } \\
\text { test on collected } \\
\text { seed. }\end{array}$ & $\begin{array}{l}\text { Column A / } \\
\text { Column B }\end{array}$ & $\begin{array}{l}\text { Column C } \times 16 \times \\
0.000988\end{array}$ & $\begin{array}{l}16 \times \text { number of } \\
\text { sites with this } \\
\text { mix }+2\end{array}$ & $\begin{array}{l}\text { (Column E } \\
\times \text { Column } \\
\text { D) } / 16\end{array}$ & Column $\mathrm{F} \times 2$ & $\begin{array}{l}\text { Column } \mathrm{G}+(0.1 \\
\text { to } 0.2 \text { or so for } \\
\text { rounding })\end{array}$ \\
\hline $\begin{array}{l}\text { Rate found: } 1-2 \text {; } \\
\quad \text { use } 2\end{array}$ & 1 & 2 & 0.031616 & 18 & 0.035568 & 0.071136 & .07 rounded to .15 \\
\hline
\end{tabular}




\section{Appendix 2. Ecoregion Species Lists}

These mixes have previously been used in these ecoregions: Chihuahuan Desert, Colorado Plateau, Sonoran Desert, Southeast Arizona Grassland, and Mojave Desert. The mix designation for each of these is only for that region, so "warm" in one ecoregion is not the same as "warm" in another. The Colorado Plateau ecoregion had four types of sites, so the mixes were divided into: cool, cool/medium, medium/warm, and warm.

Table 2.1. Chihuahuan Desert ecoregion species.

[USDA, U.S. Department of Agriculture; $\mathrm{g} / \mathrm{m}^{2}$, grams per square meter; lb/acre, pounds per acre]

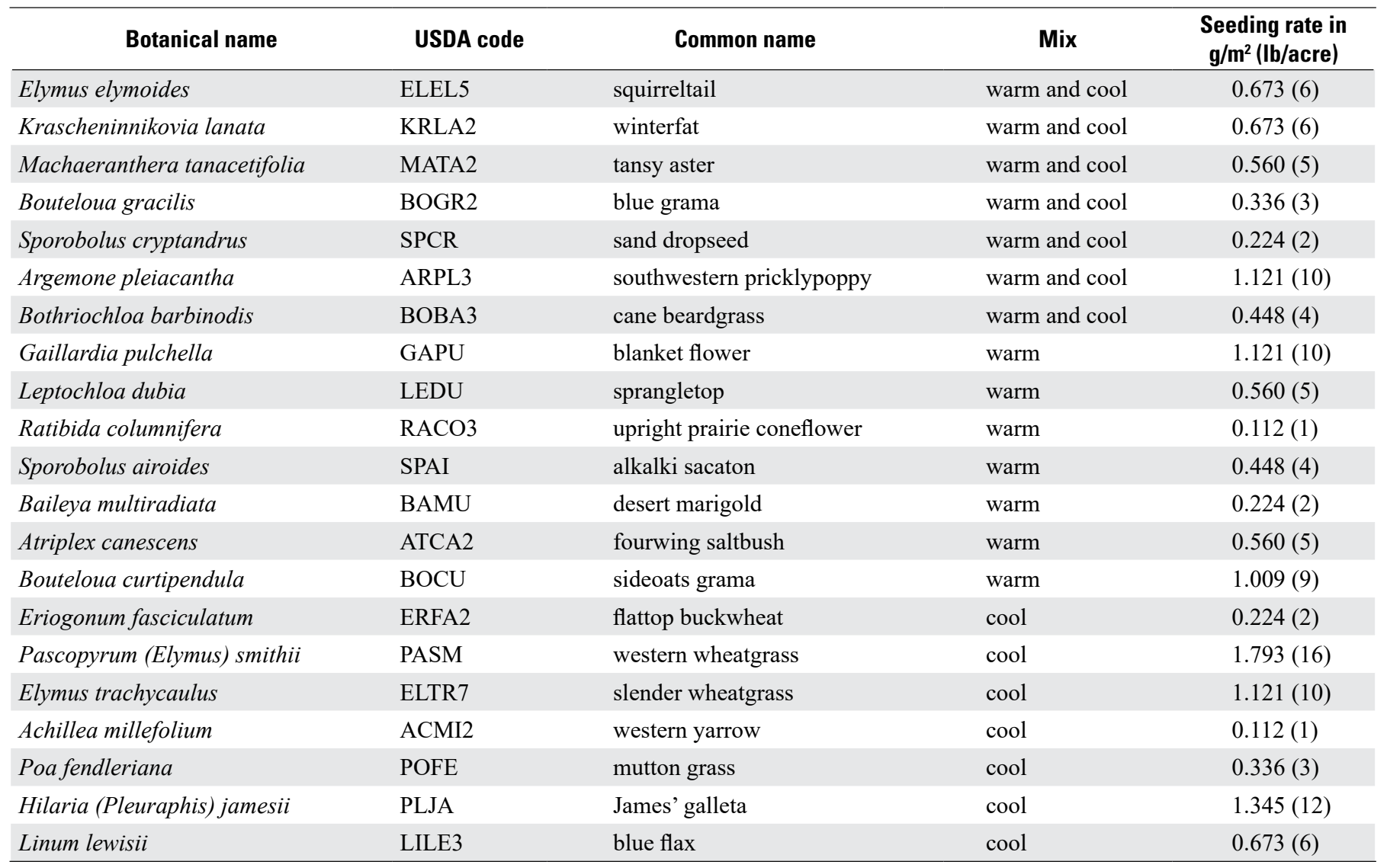


Table 2.2. Colorado Plateau ecoregion species.

[USDA, U.S. Department of Agriculture; $\mathrm{g} / \mathrm{m}^{2}$, grams per square meter; lb/acre, pounds per acre]

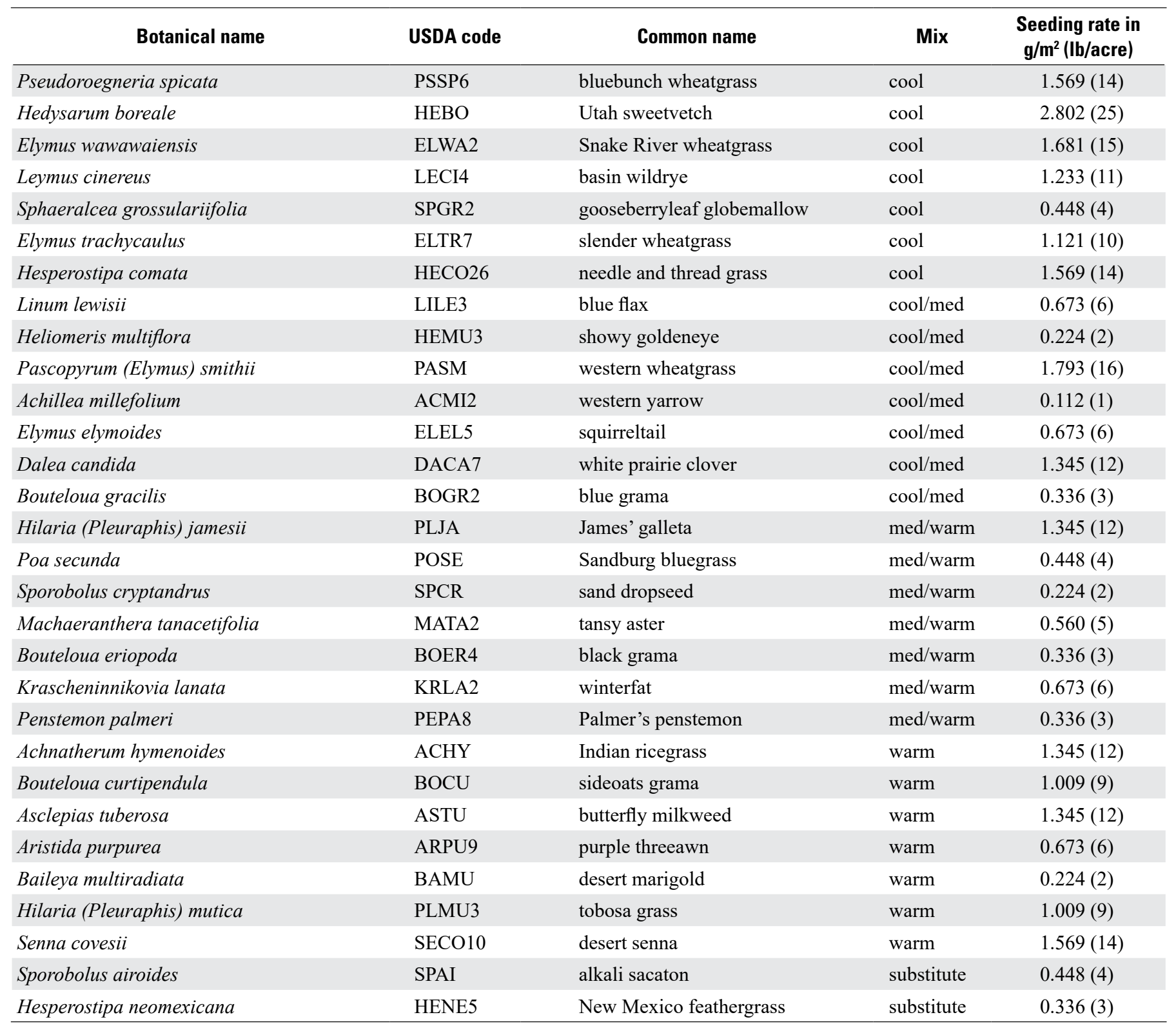


Table 2.3. Mojave Desert ecoregion species.

[USDA, U.S. Department of Agriculture; $\mathrm{g} / \mathrm{m}^{2}$, grams per square meter; lb/acre, pounds per acre]

\begin{tabular}{|c|c|c|c|c|}
\hline Botanical name & USDA code & Common name & Mix & $\begin{array}{l}\text { Seeding rate in } \\
\mathrm{g} / \mathrm{m}^{2} \text { (Ib/acre) }\end{array}$ \\
\hline Phacelia tanacetifolia & PHTA & lacey phacelia & cool & $0.280(2.5)$ \\
\hline Eriogonum fasciculatum & ERFA2 & flattop buckwheat & cool & $0.224(2)$ \\
\hline Baileya multiradiata & BAMU & desert marigold & cool & $0.224(2)$ \\
\hline Achnatherum hymenoides & ACHY & Indian ricegrass & cool & $1.121(10)$ \\
\hline Layia glandulosa & LAGL5 & tidytips & cool & $0.112(1)$ \\
\hline Atriplex canescens & ATCA2 & fourwing saltbush & warm & $0.448(4)$ \\
\hline Sphaeralcea ambigua & SPAM2 & desert globemallow & warm & $0.448(4)$ \\
\hline Encelia farinosa & ENFA & brittlebush & warm & $0.224(2)$ \\
\hline Abronia villosa & ABVI & desert sand verbena & warm & $0.673(6)$ \\
\hline Ambrosia salsola & HYSAS & cheesebush & warm & $0.224(2)$ \\
\hline
\end{tabular}

Table 2.4. Southeast Arizona Grassland ecoregion species.

[USDA, U.S. Department of Agriculture; $\mathrm{g} / \mathrm{m}^{2}$, grams per square meter; lb/acre, pounds per acre]

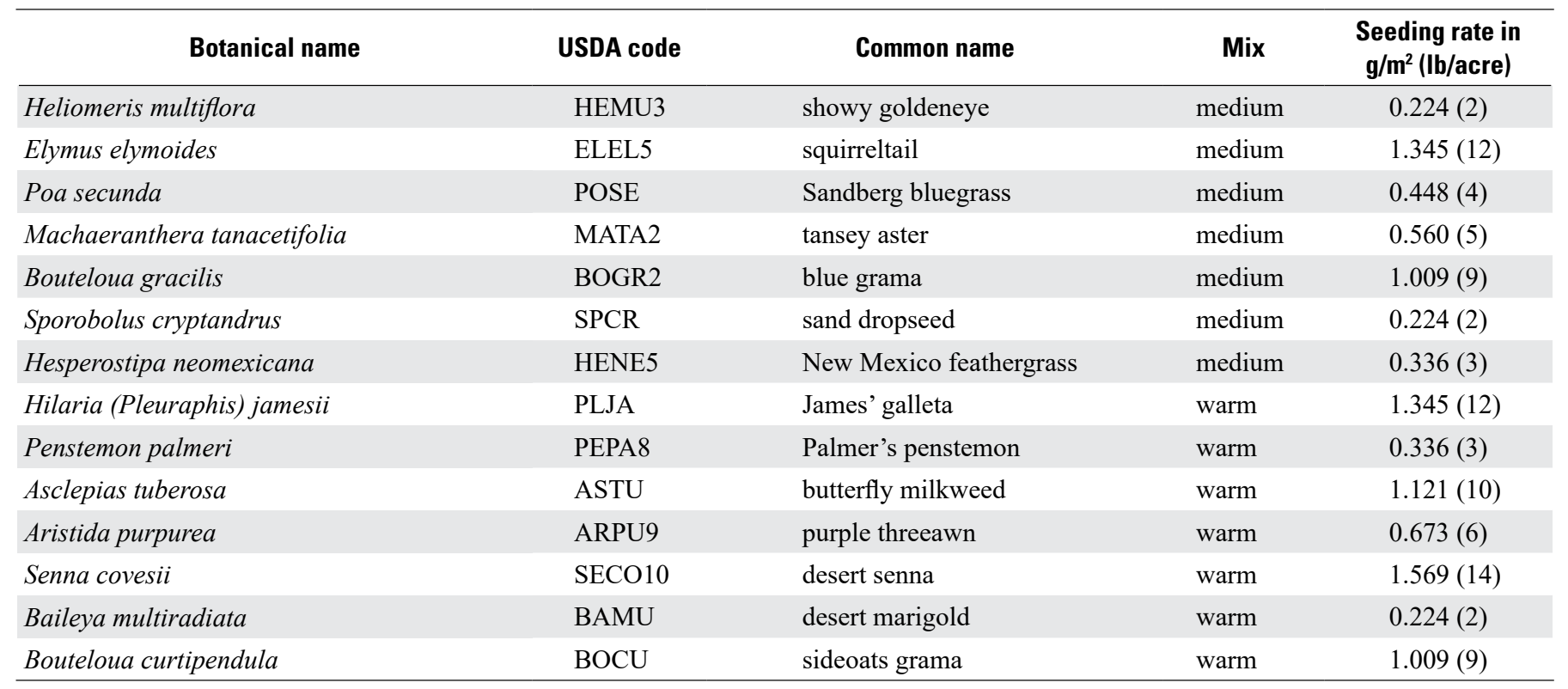


Table 2.5. Sonoran Desert ecoregion species.

[USDA, U.S. Department of Agriculture; $\mathrm{g} / \mathrm{m}^{2}$, grams per square meter; lb/acre, pounds per acre]

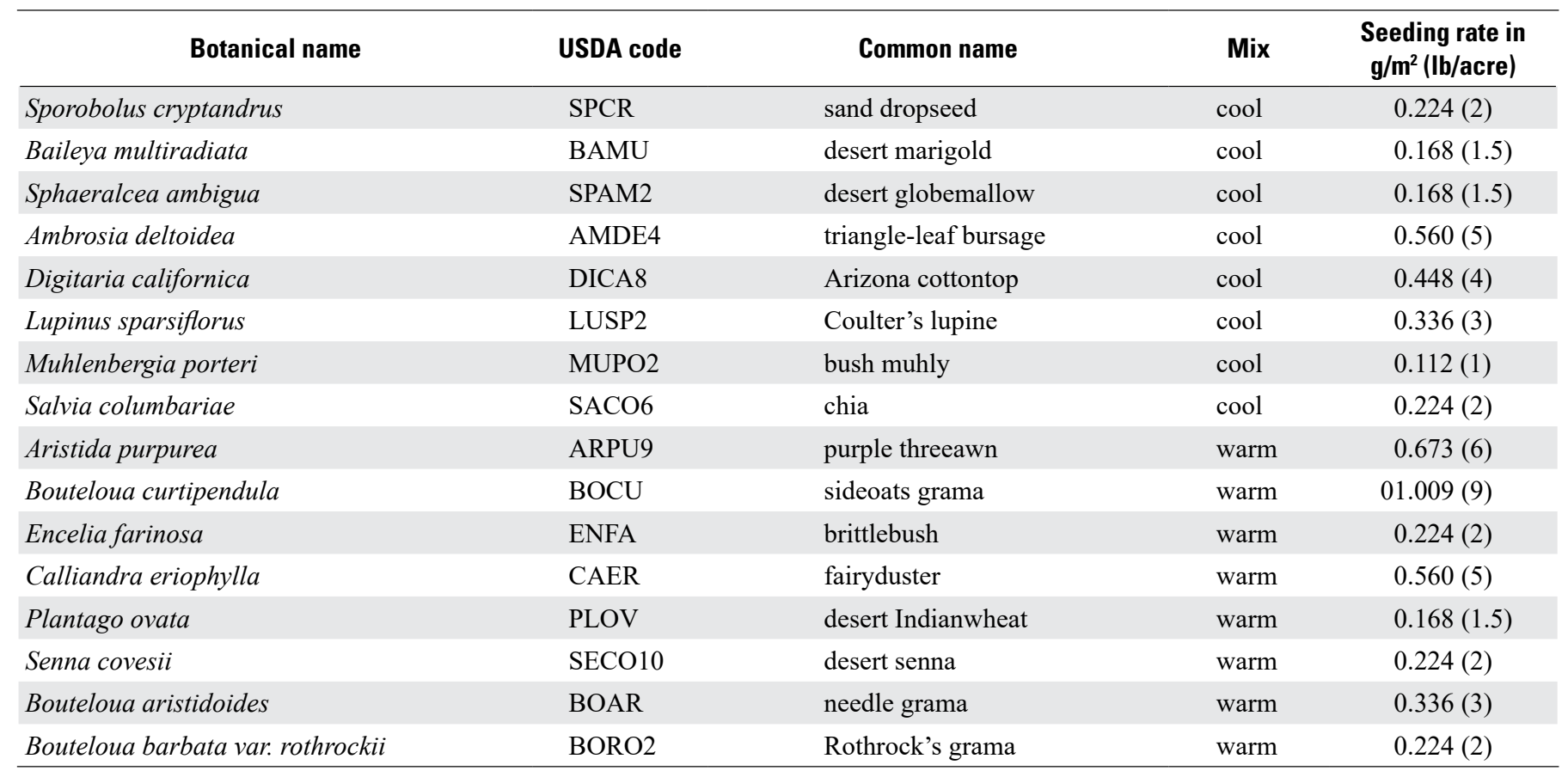




\section{Appendix 3. Equipment and Materials List}

Detailed lists of equipment, tools, and materials used in building sites. Each site needs to be protected from herbivory and granivory as recommended for the site, the guidelines below are suggests and examples of what was used at existing sites.

\section{Equipment Needed for Installation}

\section{Outplanted-Seedling Experiment}

- Water tank, hoses (for filling from tank and for refilling tank), Buckets

- Soil augers, power and hand

- Gas tank (mixed) for soil auger

- Seedlings

- Trowels for clearing drilled holes

- Measuring cups for watering plant holes

- Wooden dowels for removing plants from pots

- Wooden hole template and spray paint

- Kneeling cushions

- Plant layout design

- Watering can

- Small amount of herbicide

\section{Seeded Experiment}

- Seed packets

- Shovels/McLeods for pitting/tamping/raking

- Mulch bag, buckets for spreading

- Play sand for seed spreading

- Measuring cup

- ConMods

- Mallets

- Landscape staples

- Spike nails for subplot marking

- Small quadrat for subplot marking

- Meter stick/measuring tape for subplot measuring

\section{Additional Items}

- Water jug

- Shade tent

\section{Materials}

\section{For Each Site}

- Rain gage (optional)

- Machine or vegetable oil for adding to rain gage to prevent evaporation

- 144 rebar plot markers $-1 \mathrm{~cm}$ diameter by $38 \mathrm{~cm}$ long

- 144 PVC-pipe pieces for marking rebar-at least 1-cm internal diameter by $15 \mathrm{~cm}$ long

- Spray paint for color-coding PVC pipe

- 36 plot tags

\section{Seeding Treatment Materials}

- 32 ConMods made of 1-cm-mesh hardware cloth

- 160 ground staples to secure ConMods, five per ConMod $-6 \times 1 \times 6$ in

- Wood mulch, approximately $0.2 \mathrm{~m}^{3}$ per site

- 144 spike nails for germination-monitoring subplots $-1 \times 25 \mathrm{~cm}$

\section{Perimeter Fencing}

If cattle are present and barbed-wire fencing is required, the fence will be built with 1.6-m T-posts every $3 \mathrm{~m}$, plus an extra four posts at each corner for support bracing. Lengths below are for a barbed-wire fence built using three strands of barbed wire. Sometimes fences are recommended to have 4 or 5 strands if ungulate pressure is high. In addition, some managers may prefer using smooth wire for the bottom strand for antelope.

For a $50 \times 50-m$ site:

- T-posts for fencing, 85 per site

- Barbed wire, $900 \mathrm{~m}$ per site

- Corner bracing kits for fence, four per site 
- Fencing wire, one roll per site

Note: Ensure that fence wire clips are included with purchase of T-posts to attach wire to posts. These generally come with T-post purchases but sometimes are accidentally not included!

\section{Special Types of Fencing}

If the chance of granivory or herbivory by rabbits, javelinas, or rodents is high, additional fencing can be installed around seed plots, seedling plots, or both. This fencing can be supported by the existing 6-foot (ft) T-posts or by using 3-ft T-posts as needed around portions of the experiment. Short fencing can be added to reduce granivory and (or) herbivory. The javelina fence will also keep out rabbits. The type of fencing will be site specific and should be informed by the land manager. Additional granular repellents can be applied to deter rabbits, rodents, and ants.

\section{Small-Mammal Fencing}

Small-mammal fencing includes flashing, which prevents small animals from climbing into the experiment site. Holes can be pounded into the top of the flashing about every $45 \mathrm{~cm}$, using a nail and board. Attach the flashing to the hardware cloth using hog rings. Alternatively, holes can be installed at the bottom of the flashing to wire it to the cloth.
- Hardware cloth - a maximum of 0.6-cm mesh and at least $90 \mathrm{~cm}$ tall for partial burial at the bottom to secure cloth and prevent burrowing

- Flashing to run along the top of hardware cloth, preventing climbing rodents $-15 \mathrm{~cm}$ tall

- Pack of hog rings to attach flashing to hardware cloth

- Ground staples to secure partially buried hardware cloth-15-cm long

- Short T-posts to divide site, placed every $2 \mathrm{~m}$

Rabbit Fencing

- Poultry netting $-2 \mathrm{~cm} \times 1 \mathrm{~m}$

- Ground staples to secure partially buried chicken wire$15 \times 2 \times 15 \mathrm{~cm}$

\section{Javelina Fencing}

- Welded wire fencing- $5 \times 10$-cm mesh, $3 \mathrm{~m}$ tall

Note: Welded wire can be used instead of lower-two barbed-wire strands at sites where javelina are the only ungulate. 


\section{Appendix 4. Propagation Protocols}

Native seeds often need treatments before sowing in the greenhouse to remove dormancy adaptations. The following protocols were used by growers who installed the outplantedseedling experiment. Check with the RestoreNet coordinators to see if more updated protocols exist before sowing species in the greenhouse for the outplanted-seedling experiment.

\section{Colorado Plateau}

All species were placed in the refrigerator for at least 30 days prior to sowing. Additional species-specific protocols are as follows:

- Hedysarum boreale-Soak in lukewarm water for 24 hours prior to sowing

- Penstemon palmeri-Soak in 5-percent solution of gibberellic acid prior to sowing

- Sphaeralcea grossularifolia-Pour boiling water over seed, leave to soak for 24 hours prior to sowing.

- Sporobolus cryptandrus and Machaeranthera tanacetifolia - Seed directly on top of soil rather than at depth.

\section{Mojave Desert}

All species were soaked overnight prior to sowing. Additional species-specific protocols performed before soaking are as follows:
- Abronia villosa - Remove seed from fruit using clippers.

- Ambrosia salsola - Remove chaff by sanding over a sieve.

- Atriplex polycarpa - Lightly scarify using sandpaper to break seeds out of fruit.

- Encelia farinosa - Sieve using a 1-mm sieve (or small enough sieve to retain seed and allow chafe to fall through). Lightly sand.

- Mirabilis laevis - Use mortar and pestle to lightly tap and crack the fruit walls. Be careful not to hit too hard and crack the inner seed.

- Sphaeralcea ambigua-Push into a 1-mm or 1.4-mm sieve to break the seed out of the coat. Slough off the chaff. Scarify with sandpaper with medium force for 1.5 minutes.

\section{Chihuahuan Desert}

All species were placed in the refrigerator for at least 30 days prior to sowing. Additional species-specific protocols are as follows:

- Atriplex canescens-Moist-cold stratify for 30 days. 


\section{Appendix 5. Seeding Installation Field Data Sheet}

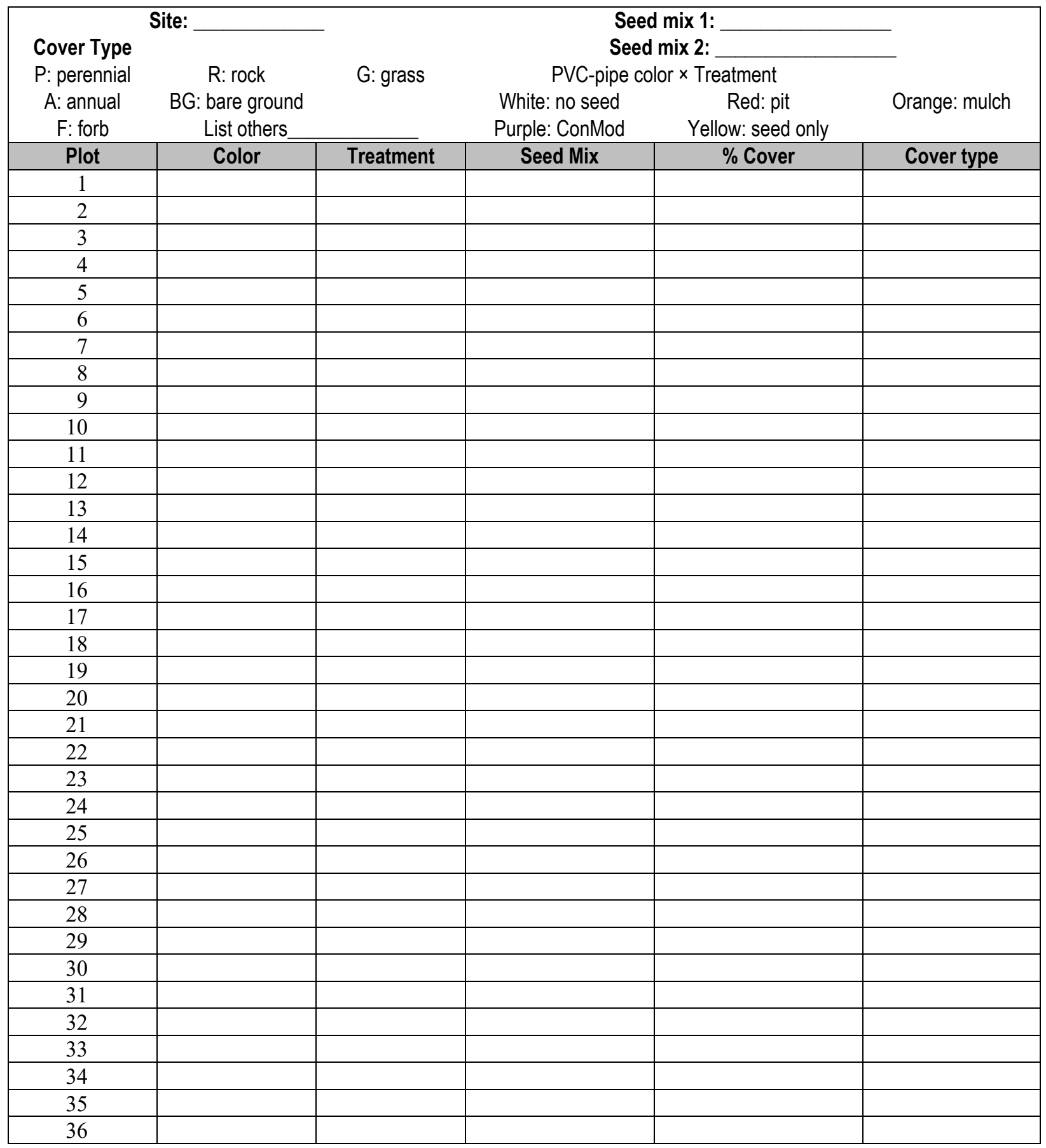

Figure 5.1. Data sheet for seeding installation. 


\section{Appendix 6. Site Assessment Data Sheet}

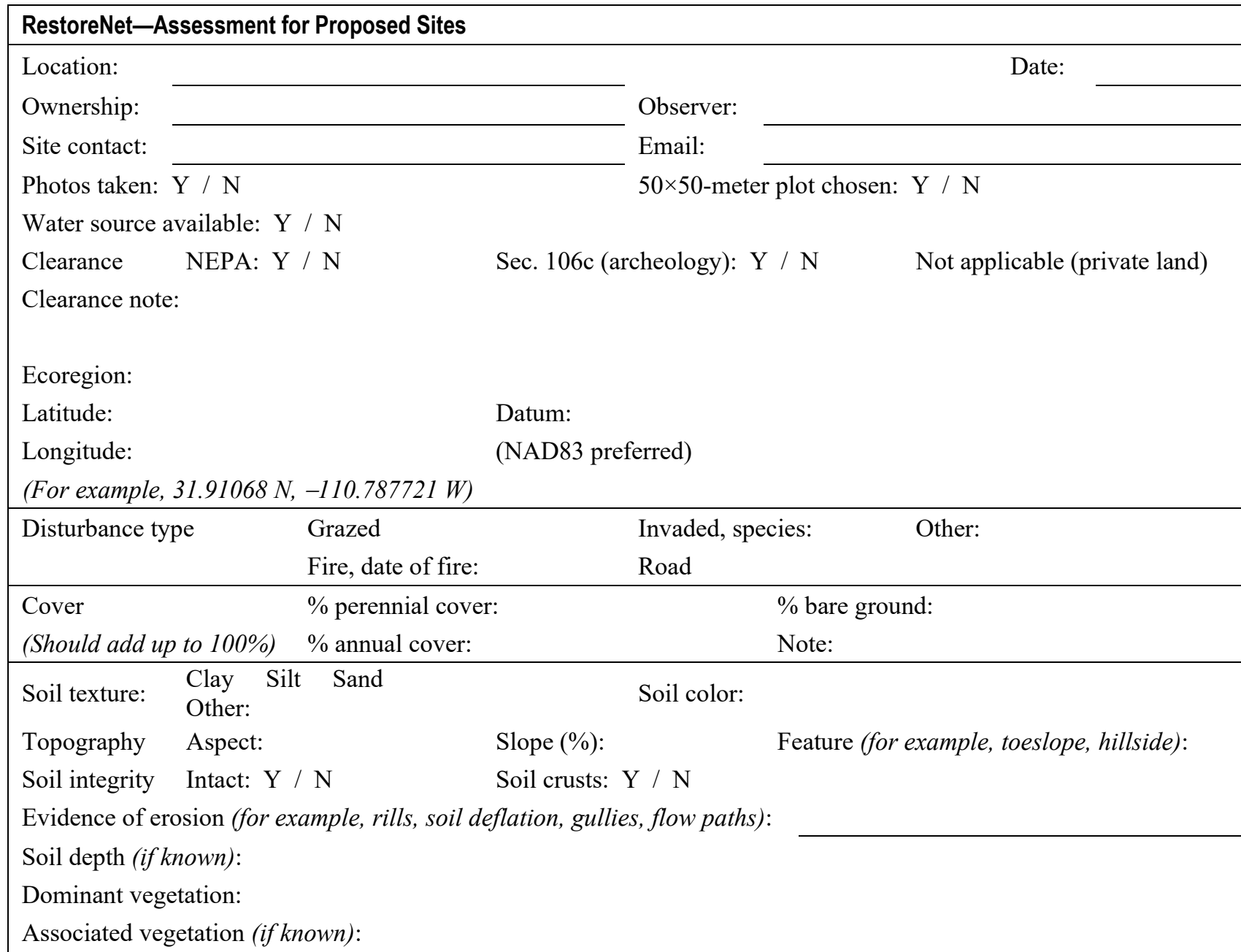

Ability of site to support native vegetation:

Stakeholder engagement- - How engaged is the partner (low, will allow the project on their land; high, really wants the results to guide projects)? How will partner use results? Does the partner have ability to help support installation, maintenance, and/or monitoring?

Site history and notes:

Please include driving directions to the location on the back of this form.

Figure 6.1. Data sheet for assessment of proposed RestoreNet site. Y, yes; N, no; \%, percent. 


\section{Appendix 7. Cost Estimate}

The estimated labor hours for installing the RestoreNet seeded experiment, only including seeding plus treatments, are 50 to 108 hours (table 7.1). The range is mostly due to site preparation time, which is the time it takes to remove any existing vegetation and level the site. Depending on the level of monitoring frequency decided, monitoring can take between 24 and 72 total hours (table 7.1). The range accounts for the time it takes as more seedlings germinate and need to be counted. These estimates do not include travel time to the site.

If the site includes the outplanted-seedling experiment, the estimated labor hours are between 170 and 384 (table 7.1). The range reflects the time it takes to plant the seedlings at a site, which is largely a factor of soil type. Loose soils require less time for digging and planting than harder, more clayey soils. There is a small range for watering and monitoring the seedlings, depending on variables in water access and growth rate, respectively.

The estimated costs to install a single $50 \times 50$-m experiment site is $\$ 2,138.50$ in 2020 dollars (table 7.2). The outplanted-seedling experiment would cost an estimated additional $\$ 984.50$ (table 7.2); however, this depends on the tools and equipment already available, including a water tank and digging augers. The cost also depends on the amount of fencing needed at the site. Details for items in the table 7.2 summary table are found in "Perimeter Fencing" and "Special Types of Fencing" sections.

Table 7.1. Estimated labor for installation and watering

[min., minimum; max., maximum; - , not applicable]

\begin{tabular}{lcccc}
\hline \multicolumn{1}{c}{ Labor } & \multicolumn{3}{c}{ People hours $^{\mathbf{1}}$} \\
\cline { 2 - 6 } & $\begin{array}{c}\text { Min.-no } \\
\text { outplanting }\end{array}$ & $\begin{array}{c}\text { Max.-no } \\
\text { outplanting }\end{array}$ & $\begin{array}{c}\text { Min.-with } \\
\text { outplanting }\end{array}$ & $\begin{array}{c}\text { Max.-with } \\
\text { outplanting }\end{array}$ \\
\hline Material prep & 8 & 12 & 12 & 16 \\
\hline Site prep & 16 & 60 & 16 & 60 \\
\hline Fencing and marking plots & 20 & 26 & 20 & 26 \\
\hline Installation seed treatments & 6 & 10 & 6 & 10 \\
\hline Installation seedlings - outplanting only (1,600 plants) & - & - & 96 & 224 \\
\hline Watering seedlings - outplanting only (8-16 times) & - & - & 20 & 48 \\
\hline Monitoring (4-12 times, outplanting-4 times only) & 24 & 72 & 40 & 90 \\
\hline Total hours per site & $\mathbf{7 4}$ & $\mathbf{1 8 0}$ & $\mathbf{2 1 0}$ & $\mathbf{4 7 4}$ \\
\hline
\end{tabular}

${ }^{1}$ Does not include transit time or time growing seedlings in the greenhouse for outplanted-seedling experiment

Table 7.2. Estimated costs for tools and materials

\begin{tabular}{|c|c|c|}
\hline \multirow[b]{2}{*}{ Tools and materials } & \multicolumn{2}{|c|}{ Estimated cost } \\
\hline & $\begin{array}{c}\text { Standard } \\
\text { experiment }\end{array}$ & $\begin{array}{l}\text { Outplanted-seedling } \\
\text { addition }\end{array}$ \\
\hline Tools_fencing & 203 & \\
\hline Tools_-plot setup & 389 & 30 \\
\hline Tools_-planting (outplanting only) & & 345 \\
\hline Tools-watering (outplanting only) & & 417 (tank estimate) \\
\hline Fencing - per site, no chicken wire & 468 & \\
\hline Chicken wire fencing addition & 405 & \\
\hline Rodent and javelina fencing addition & 385 & \\
\hline Materials_-plot setup & 146.50 & 46.50 \\
\hline Materials_-seeding and planting & 142 & 146 \\
\hline Total & 2138.50 & 984.50 \\
\hline
\end{tabular}




\section{Appendix 8. Example of Germination Monitoring Data Sheet}

\begin{tabular}{|c|c|c|c|c|c|c|c|}
\hline \multicolumn{4}{|c|}{ RestoreNet Monitoring Datasheet } & \multicolumn{3}{|c|}{$\begin{array}{l}\text { Date: } \\
\text { Recorder: }\end{array}$} & \multirow[t]{2}{*}{ Page___ of } \\
\hline \multicolumn{4}{|c|}{$\begin{array}{l}\text { Site: } \\
\text { Observer(s): } \\
\text { Rain gauge amount (inches to } 2 \text { decimal places): }\end{array}$} & \multicolumn{3}{|c|}{$\begin{array}{l}\text { Recorder: } \\
\quad \text { Dumped water? }\end{array}$} & \\
\hline \multicolumn{4}{|c|}{$\begin{array}{l}\text { PLOT \#: } \\
\text { Full plot }(2 \times 2 \mathrm{~m}) \text { color: } \\
\text { Seeded species only: }\end{array}$} & \multicolumn{3}{|l|}{ Notes*: } & Species*: \\
\hline \multicolumn{3}{|c|}{ Subplot $(0.25 \times 0.25 \mathrm{~m})$ sampling: } & \multicolumn{4}{|c|}{ Identification characteristics: } & \\
\hline $\begin{array}{l}\text { Species } \\
\text { code }\end{array}$ & $\begin{array}{l}\text { Seedling } \\
\text { count }\end{array}$ & $\begin{array}{l}\text { Average } \\
\text { height }(\mathrm{mm})\end{array}$ & $\begin{array}{l}\text { Functional } \\
\text { (grass/forb }\end{array}$ & $\begin{array}{l}\text { group } \\
\text { (shrub) }\end{array}$ & $\begin{array}{l}\text { Seeded? } \\
\text { (Yes/No) }\end{array}$ & $\begin{array}{l}\text { Certainty } \\
\text { of ID (1-3) }\end{array}$ & $\begin{array}{l}\text { Species notes/Description of } \\
\text { unknown }\end{array}$ \\
\hline & & & & & & & \\
\hline & & & & & & & \\
\hline & & & & & & & \\
\hline & & & & & & & \\
\hline & & & & & & & \\
\hline & & & & & & & \\
\hline & & & & & & & \\
\hline & & & & & & & \\
\hline & & & & & & & \\
\hline
\end{tabular}

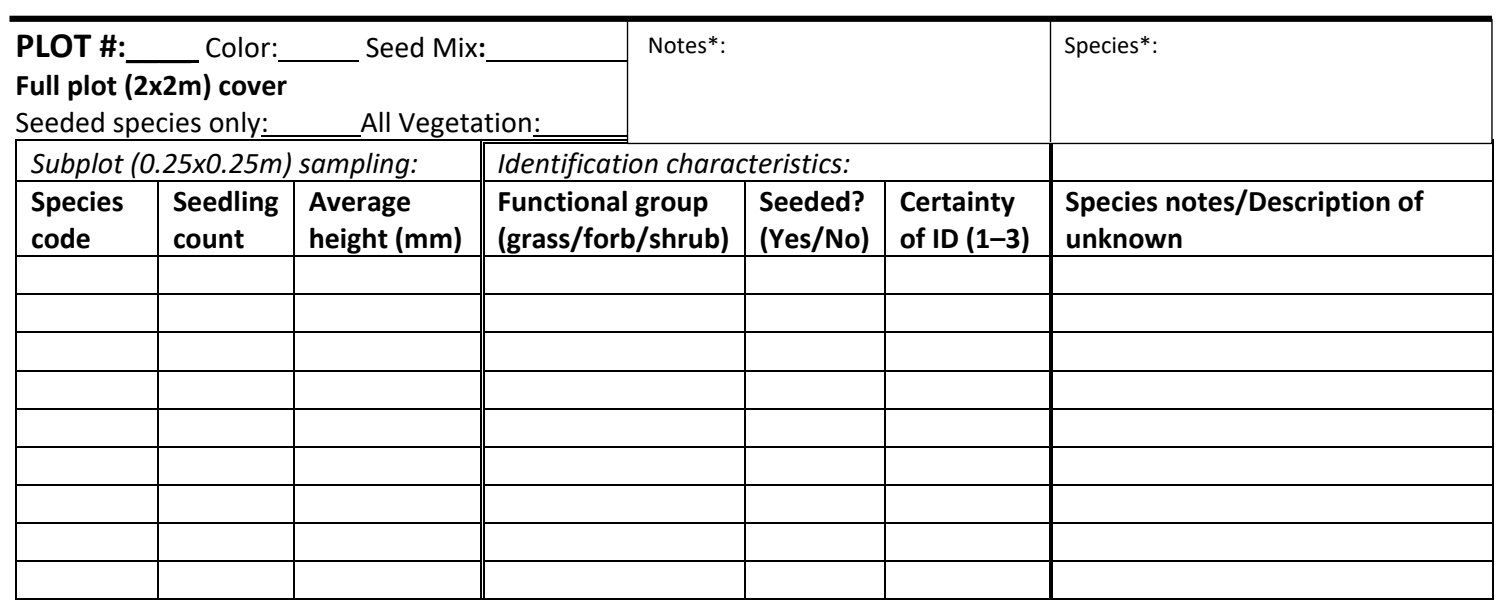

\begin{tabular}{|c|c|c|c|c|c|c|c|}
\hline \multicolumn{4}{|c|}{$\begin{array}{l}\text { PLOT \#: } \\
\text { Full plot }(2 \times 2 \mathrm{~m}) \text { color: } \\
\text { Seeded species only: }\end{array}$} & \multicolumn{3}{|l|}{ Notes*: } & \multirow{3}{*}{$\begin{array}{l}\text { Species*: } \\
\begin{array}{l}\text { Species notes/Description of } \\
\text { unknown }\end{array} \\
\end{array}$} \\
\hline \multicolumn{3}{|c|}{ Subplot $(0.25 \times 0.25 \mathrm{~m})$ sampling: } & \multicolumn{4}{|c|}{ Identification characteristics: } & \\
\hline $\begin{array}{l}\text { Species } \\
\text { code }\end{array}$ & $\begin{array}{l}\text { Seedling } \\
\text { count }\end{array}$ & $\begin{array}{l}\text { Average } \\
\text { height }(\mathrm{mm})\end{array}$ & $\begin{array}{l}\text { Func } \\
\text { (gras }\end{array}$ & $\begin{array}{l}\text { Igroup } \\
\text { b/shrub) }\end{array}$ & $\begin{array}{l}\text { Seeded? } \\
\text { (Yes/No) }\end{array}$ & $\begin{array}{l}\text { Certainty } \\
\text { of ID (1-3) }\end{array}$ & \\
\hline & & & & & & & \\
\hline & & & & & & & \\
\hline & & & & & & & \\
\hline & & & & & & & \\
\hline & & & & & & & \\
\hline & & & & & & & \\
\hline & & & & & & & \\
\hline & & & & & & & \\
\hline & & & & & & & \\
\hline
\end{tabular}

*Notes should include: \% mulch remaining in plot/subplot; \% pit filled; sediment trapped by ConMod; signs of erosion. Species box should include additional species found in whole plot but not recorded in subplots.

Figure 8.1. Data sheet for monitoring a RestoreNet site 


\section{Appendix 9. Outplanting Layout}

For the 36 plots, randomly assign 16 polyculture plots, 16 monoculture plots, 2 hole-only control plots (hole dug nothing planted), and 2 dead plant control plots (grass that was sprayed with herbicide and planted). Record this layout on a data sheet. Install a plot tag at the southwest corner of each of the plots, marking the number on the data sheet.

Assign each of the species a number from 1 to 16 . Each of the 16 polyculture plots will contain 4 individuals of each of the 4 species listed, for a total of 16 plants. During installation, randomly assign each species a location in the plot. Mark on a data sheet where each species was located inside the plots, and the orientation of the plots (mark the southwest corner on the data sheet). Use these data to make a data sheet like the one in figure 21.

\begin{tabular}{|c|c|c|c|c|}
\hline & Species 1 & Species 2 & Species 3 & Species 4 \\
\hline Poly1 & Sp. 1 & Sp. 2 & Sp. 3 & Sp. 4 \\
\hline Poly2 & Sp. 5 & Sp. 1 & Sp. 6 & Sp. 7 \\
\hline Poly3 & Sp. 8 & Sp. 5 & Sp. 9 & Sp. 10 \\
\hline Poly4 & Sp. 4 & Sp. 8 & Sp. 11 & Sp. 12 \\
\hline Poly5 & Sp. 7 & Sp. 4 & Sp. 13 & Sp. 14 \\
\hline Poly6 & Sp. 10 & Sp. 7 & Sp. 2 & Sp. 15 \\
\hline Poly7 & Sp. 12 & Sp. 10 & Sp. 1 & Sp. 16 \\
\hline Poly8 & Sp. 14 & Sp. 12 & Sp. 5 & Sp. 3 \\
\hline Poly9 & Sp. 15 & Sp. 14 & Sp. 8 & Sp. 6 \\
\hline Poly10 & Sp. 16 & Sp. 15 & Sp. 4 & Sp. 9 \\
\hline Poly11 & Sp. 3 & Sp. 16 & Sp. 7 & Sp. 11 \\
\hline Poly12 & Sp. 6 & Sp. 3 & Sp. 10 & Sp. 13 \\
\hline Poly13 & Sp. 9 & Sp. 6 & Sp. 12 & Sp. 2 \\
\hline Poly14 & Sp. 11 & Sp. 9 & Sp. 14 & Sp. 1 \\
\hline Poly15 & Sp. 13 & Sp. 11 & Sp. 15 & Sp. 5 \\
\hline Poly16 & Sp. 2 & Sp. 13 & Sp. 16 & Sp. 8 \\
\hline
\end{tabular}

Figure 9.1. Chart showing layout of outplanted-seedling site 
Moffett Field Publishing Service Center

Manuscript approved November 16, 2021

Edited by Regan Austin

Illustration support by Kimber Petersen

Layout by Cory Hurd 
